\title{
Analytical and Numerical Study of the Onset of Electroconvection in a Dielectric Nanofluid Saturated a Rotating Darcy Porous Medium
}

\author{
Abderrahim Wakif \\ Hassan II University, Faculty of \\ Sciences Aïn Chock, \\ Laboratory of Mechanics, \\ B.P.5366 Mâarif, Casablanca, \\ Morocco
}

\author{
Zoubair Boulahia \\ Hassan II University, Faculty of \\ Sciences Aïn Chock, \\ Laboratory of Mechanics, \\ B.P.5366 Mâarif, Casablanca, \\ Morocco
}

\author{
Rachid Sehaqui \\ Hassan II University, Faculty of \\ Sciences Aïn Chock, \\ Laboratory of Mechanics, \\ B.P.5366 Mâarif, Casablanca, \\ Morocco
}

\begin{abstract}
The simultaneous effect of rotation and a vertical AC electric field on the onset of electroconvection in a horizontal dielectric nanofluid layer saturated a Darcy porous medium is investigated. The boundaries of the dielectric nanofluid layer are considered isothermal, where the vertical nanoparticle flux is zero. The resulting eigenvalue problem is solved analytically by the Galerkin weighted residuals technique (GWRT) and numerically using the power series method (PSM).The results show that the onset of electroconvection in dielectric nanofluids can be accelerated when we increase the AC electric RayleighDarcy number, the Lewis number, the nanoparticle RayleighDarcy number or the modified diffusivity ratio .On the contrary, it can be delayed when we increase the Taylor-Darcy number or the porosity of the medium .
\end{abstract}

Keywords - Linear Stability; Electroconvection; Dielectric Nanofluid; Rotation; Porous Medium; Power Series Method

\section{INTRODUCTION}

The electro-thermo-hydrodynamics (ETHD) is an interdisciplinary area dealing simultaneous complex interactions among the thermal gradient and electric field applied to a horizontal dielectric liquid (fluid or nanofluid) layer. These interactions, can be studied by performing experiments aimed to control the improvement of heat transfer by applying an electric field across a dielectric fluid, this active method has some advantages for heat transfer enhancement due the electrical effects, such as the low operational costs, rapid and smart control of enhancement, low power consumption, and so on.

In the interest to obtain a high thermal efficiency, the application of the electro-thermo-hydrodynamics transport phenomena received extensive attentions, it may be found in different areas of physics like engineering, heat exchangers, steam pipes, optical and bio-engineering devices, waste heat recovery and many others .Hence, due to the importance of the electro-thermo-hydrodynamics in practice, several studies have been carried out to assess the effect of electric field on natural convection. A temperature gradient applied to a dielectric fluid produces a gradient in the dielectric constant and electrical conductivity. Keeping this fact in mind, several problems of the onset of convection instability in a horizontal layer of dielectric fluid under the action of a vertical electric field and a vertical temperature gradient have been investigated in the past. Notable among them, we find P.H.Roberts [1] which was the first one who made an individual study on electrohydrodynamic convection by considering the dielectric constant as well as electrical conductivity as a linear function of temperature. Takashima and Aldridge [2], Peter J.Stiles [3] and Mohamed I.A Othman [4] have studied the natural convection in the presence of an applied electric field. M.Takashima [5] was the first one who studied the simultaneous effect of a vertical temperature gradient and a vertical electric field on the onset of convection in a horizontal dielectric fluid saturated a rotating layer. S. Shivakumara et al. [6-7] have investigated the onset of electrothermoconvection in a dielectric fluid saturated a rotating or non-rotating porous layer using the Galerkin technique. P.G.Siddheshwar and D.Radhakrishna [8] have performed a linear and nonlinear studies on the convective instability in dielectric fluids under a vertical temperature gradient and an AC electric field using the normal mode method and truncated representation of Fourier series.

The dielectric nanofluid may be used in an electrical apparatus and other electrical equipments such as distribution transformers, regulating transformers, shunt reactors, converter transformers, generating station units, and power transformers [9-11]. Given the importance of these types of dielectric liquids, we will examine theoretically and 
numerically the effect of a vertical AC electric field on the onset of convection in a dielectric nanofluid saturated a rotating Darcy porous medium, which is subjected to a temperature gradient, where the vertical nanoparticle flux is taken zero on the horizontal boundaries.

\section{MATHEMATICAL FORMULATION}

We consider an infinite horizontal layer of incompressible dielectric nanofluid saturated a rotating Darcy porous medium with a uniform angular velocity $\vec{\Omega}=\Omega \vec{e}_{z}$, this layer is confined between two parallel impermeable boundaries $\left(z^{*}=0, z^{*}=L\right)$ and heated from below, where the temperatures at the lower and upper boundaries are taken to be $T_{h}^{*}$ and $T_{c}^{*}$ respectively $\left(T_{h}^{*}>T_{c}^{*}\right)$, and the vertical nanoparticle flux $J_{z}^{*}$ is zero on the boundaries. The nanofluid layer is Newtonian, subjected to the gravitational field $\vec{g}=-g \vec{e}_{z}$ and also to a vertical $A C$ electric field applied across the layer, such that the lower surface is grounded and the upper surface is kept at an alternating potential whose root mean square is $\psi_{1}^{*}$ (Fig. 1).The thermo-physical properties of nanofluid (viscosity, thermal conductivity, specific heat) are assumed constant in the vicinity of the reference temperature $T_{c}^{*}$, except for the dielectric constant and the density in the Maxwell equations and the momentum equation respectively, which are based on the Oberbeck-Boussinesq approximation .The asterisks are used to distinguish the dimensional variables from the nondimensional variables (without asterisks).

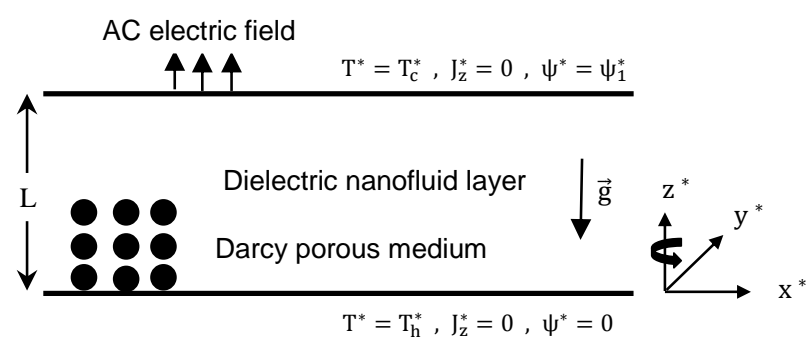

Fig. 1. Physical configuration of the problem

\section{A. Governing equations}

In the case where the centrifugal acceleration is negligible compared to the buoyancy and the electrical forces, the relevant basic equations are [10-15]:

$$
\begin{gathered}
\vec{\nabla}^{*} \cdot \vec{V}^{*}=0 \\
-\vec{\nabla}^{*} \mathrm{P}^{*}-\mathrm{K}^{-1} \mu \overrightarrow{\mathrm{V}}^{*}-2 \gamma^{-1} \rho_{0} \vec{\Omega} \times \overrightarrow{\mathrm{V}}^{*}+\overrightarrow{\mathrm{f}}_{\mathrm{e}}+\rho \overrightarrow{\mathrm{g}}=0 \\
\rho=\rho_{0}\left[1-\beta\left(\mathrm{T}^{*}-\mathrm{T}_{\mathrm{c}}^{*}\right)\right]\left(1-\chi^{*}\right)+\rho_{\mathrm{p}} \chi^{*} \\
(\rho c)_{\mathrm{m}} \frac{\partial \mathrm{T}^{*}}{\partial \mathrm{t}^{*}}+(\rho c)_{\mathrm{f}}\left(\overrightarrow{\mathrm{V}}^{*} \cdot \vec{\nabla}^{*}\right) \mathrm{T}^{*}=\mathrm{k}_{\mathrm{m}} \vec{\nabla}^{*} \mathrm{~T}^{2} \\
+\gamma(\rho \mathrm{c})_{\mathrm{p}}\left(\mathrm{D}_{\mathrm{B}} \vec{\nabla}^{*} \chi^{*} \cdot \vec{\nabla}^{*} \mathrm{~T}^{*}+\left(\frac{\mathrm{D}_{\mathrm{T}}}{\mathrm{T}_{\mathrm{c}}^{*}}\right) \vec{\nabla}^{*} \mathrm{~T}^{*} \cdot \vec{\nabla}^{*} \mathrm{~T}^{*}\right) \\
\frac{\partial \chi^{*}}{\partial \mathrm{t}^{*}}+\gamma^{-1}\left(\overrightarrow{\mathrm{V}}^{*} \cdot \vec{\nabla}^{*}\right) \chi^{*}=\mathrm{D}_{\mathrm{B}} \vec{\nabla}^{*} \chi^{2}+\left(\frac{\mathrm{D}_{\mathrm{T}}}{\mathrm{T}_{\mathrm{c}}^{*}}\right) \vec{\nabla}^{*} \mathrm{~T}^{2}
\end{gathered}
$$

Where $\vec{V}^{*}\left(u^{*}, v^{*}, w^{*}\right)$ is the Darcy's velocity, $t^{*}$ is the time, $\rho_{0}$ is the nanofluid density at reference temperature $T_{c}^{*}, P^{*}$ is the pressure , $K, \gamma, \mu, \rho$ and $k_{m}$ are the permeability, the porosity of the medium, the viscosity, the density and the effective thermal conductivity of nanofluid respectively, $\rho_{p}$ is the density of nanoparticles, $\beta$ is the thermal expansion coefficient, $\chi^{*}$ is the volumetric fraction of nanoparticles, $(\rho c)_{p}$ and $(\rho c)_{f}$ are the heat capacity of nanoparticles and base fluid respectively, $(\rho c)_{m}$ is the effective heat capacity of nanofluid, $D_{B}$ is the Brownian diffusion coefficient, $D_{T}$ is the thermophoretic diffusion coefficient, $\vec{\nabla}^{*}$ is the vector differential operator and $\vec{f}_{e}$ is the force of electrical origin which can be expressed by Landau and Lifshitz [16] as follows:

$$
\overrightarrow{\mathrm{f}}_{\mathrm{e}}=\rho_{\mathrm{e}} \overrightarrow{\mathrm{E}}^{*}-\frac{1}{2}\left(\overrightarrow{\mathrm{E}}^{*} \cdot \overrightarrow{\mathrm{E}}^{*}\right) \vec{\nabla}^{*} \epsilon^{*}+\frac{1}{2} \vec{\nabla}^{*}\left[\rho \frac{\partial \epsilon^{*}}{\partial \rho}\left(\overrightarrow{\mathrm{E}}^{*} \cdot \overrightarrow{\mathrm{E}}^{*}\right)\right]
$$

Where $\vec{E}^{*}$ is the root mean square value of the electric field, $\rho_{e}$ is the charge density and $\epsilon^{*}$ is the dielectric constant.

In the equation (6), the last electrostriction term can be grouped with the pressure $P^{*}$ in the equation (2) and it has no effect on an incompressible nanofluid. The first term on the right hand side is the Coulomb force due to a free charge and the second term depends on the gradient of $\epsilon^{*}$. If an $A C$ electric field is applied at a frequency much higher than the reciprocal of the electrical relaxation time, the free charge doesn't have time to accumulate. Moreover, the electrical relaxation times of most dielectric liquids appear to be sufficiently long to prevent the buildup of free charge at standard power line frequencies. At the same time, the dielectric loss at these frequencies is so low that it makes no significant contribution to the temperature field. Under the circumstances, only the force induced by non-uniformity of the dielectric constant is considered. Furthermore, since the second term in the above equation depends on $\vec{E}^{*} \cdot \vec{E}^{*}$ rather than $\vec{E}^{*}$ and the variation of $\vec{E}^{*}$ is very rapid, the root mean square value of $\vec{E}^{*}$ can be assumed as the effective value. In other words, we can treat the $A C$ electric field as the $D C$ electric field whose strength is equal to the root mean square value of the $A C$ electric field $[10,11,17]$.

Since there is no free charge, the relevant Maxwell equations are:

$$
\begin{gathered}
\vec{\nabla}^{*} \times \overrightarrow{\mathrm{E}}^{*}=\overrightarrow{0} \\
\vec{\nabla}^{*} \cdot\left(\epsilon^{*} \overrightarrow{\mathrm{E}}^{*}\right)=0
\end{gathered}
$$

In view of the equation (7), $\vec{E}^{*}$ can be expressed as:

$$
\overrightarrow{\mathrm{E}}^{*}=-\vec{\nabla}^{*} \psi^{*}
$$

Where $\psi^{*}$ is the root mean square value of the electric potential, such that the dielectric constant $\epsilon^{*}$ is assumed to be in the form:

$$
\epsilon^{*}=\epsilon_{0}\left[1-e\left(\mathrm{~T}^{*}-\mathrm{T}_{\mathrm{c}}^{*}\right)\right]
$$

Here $e$ is the thermal expansion coefficient of dielectric constant, it's assumed to be very small $\left(0<e \Delta T^{*} \ll 1\right)$.If we consider that the temperature is constant and the vertical nanoparticle flux $J_{z}^{*}$ is zero on the boundaries, we can write the boundary conditions under the Darcy's model as follows:

$$
\begin{array}{llll}
\mathrm{w}^{*}=0 & ; \mathrm{T}^{*}=\mathrm{T}_{\mathrm{h}}^{*} ; \mathrm{J}_{\mathrm{z}}^{*}=0 & \text { at } & \mathrm{z}^{*}=0 \\
\mathrm{w}^{*}=0 & ; \mathrm{T}^{*}=\mathrm{T}_{\mathrm{c}}^{*} ; \mathrm{J}_{\mathrm{z}}^{*}=0 & \text { at } & \mathrm{z}^{*}=\mathrm{L}
\end{array}
$$


Such that:

$$
\mathrm{J}_{\mathrm{z}}^{*}=-\rho_{\mathrm{p}}\left[\mathrm{D}_{\mathrm{B}} \frac{\partial \chi^{*}}{\partial \mathrm{z}^{*}}+\left(\frac{\mathrm{D}_{\mathrm{T}}}{\mathrm{T}_{\mathrm{c}}^{*}}\right) \frac{\partial \mathrm{T}^{*}}{\partial \mathrm{z}^{*}}\right]
$$

If we consider the following dimensionless variables:

$$
\begin{gathered}
\left(\mathrm{x}^{*}, \mathrm{y}^{*}, \mathrm{z}^{*}\right)=\mathrm{L}(\mathrm{x}, \mathrm{y}, \mathrm{z}) ; \mathrm{t}^{*}=\frac{\sigma \mathrm{L}^{2}}{\alpha_{\mathrm{m}}} \mathrm{t} ; \overrightarrow{\mathrm{V}}^{*}=\frac{\alpha_{\mathrm{m}}}{\mathrm{L}} \overrightarrow{\mathrm{V}} ; \mathrm{P}^{*}=\frac{\mu \alpha_{\mathrm{m}}}{\mathrm{K}} \mathrm{P} \\
\mathrm{T}^{*}-\mathrm{T}_{\mathrm{c}}^{*}=\Delta \mathrm{T}^{*} \mathrm{~T} ; \chi^{*}-\chi_{0}^{*}=\chi_{0}^{*} \chi ; \mathrm{J}_{\mathrm{z}}=-\frac{\mathrm{L}}{\rho_{\mathrm{p}} \mathrm{D}_{\mathrm{B}} \chi_{0}^{*}} \mathrm{~J}_{\mathrm{z}}^{*} \\
\overrightarrow{\mathrm{E}}^{*}=\mathrm{e} \Delta \mathrm{T}^{*} \mathrm{E}_{0}^{*} \overrightarrow{\mathrm{E}} ; \psi^{*}=\mathrm{e} \Delta \mathrm{T}^{*} \mathrm{LE}_{0}^{*} \psi ; \epsilon^{*}=\epsilon_{0} \epsilon
\end{gathered}
$$

Then, we can get for a nanofluid at low concentration of nanoparticles, the following non-dimensional equations:

$$
\begin{gathered}
\vec{\nabla} \cdot \vec{V}=0 \\
-\vec{\nabla}\left(\mathrm{P}+\mathrm{R}_{\mathrm{M}} \mathrm{z}-\frac{1}{2} \mathrm{R}_{\mathrm{ae}} \rho \frac{\partial \epsilon}{\partial \rho}(\overrightarrow{\mathrm{E}} \cdot \overrightarrow{\mathrm{E}})\right)-\overrightarrow{\mathrm{V}}+\sqrt{\mathrm{T}_{\mathrm{A}}}\left(\mathrm{ve}_{\mathrm{x}}-\mathrm{ue}_{\mathrm{y}}\right) \\
-\frac{1}{2} \mathrm{R}_{\mathrm{ae}}(\overrightarrow{\mathrm{E}} \cdot \overrightarrow{\mathrm{E}}) \vec{\nabla} \epsilon+\left(\mathrm{R}_{\mathrm{a}} \mathrm{T}-\mathrm{R}_{\mathrm{N}} \chi\right) \overrightarrow{\mathrm{e}}_{\mathrm{z}}=0 \\
\frac{\partial \mathrm{T}}{\partial \mathrm{t}}+(\overrightarrow{\mathrm{V}} \cdot \vec{\nabla}) \mathrm{T}=\vec{\nabla}^{2} \mathrm{~T}+\mathrm{N}_{\mathrm{B}} \mathrm{L}_{\mathrm{e}}^{-1} \vec{\nabla} \chi \cdot \vec{\nabla} \mathrm{T}+\mathrm{N}_{\mathrm{A}} \mathrm{N}_{\mathrm{B}} \mathrm{L}_{\mathrm{e}}^{-1} \vec{\nabla} \mathrm{T} \cdot \vec{\nabla} \mathrm{T} \\
\sigma^{-1} \frac{\partial \chi}{\partial \mathrm{t}}+\gamma^{-1}(\overrightarrow{\mathrm{V}} \cdot \vec{\nabla}) \chi=\mathrm{L}_{\mathrm{e}}^{-1} \vec{\nabla}^{2} \chi+\mathrm{N}_{\mathrm{A}} \mathrm{L}_{\mathrm{e}}^{-1} \vec{\nabla}^{2} \mathrm{~T} \\
\vec{\nabla} \times \overrightarrow{\mathrm{E}}=\overrightarrow{0} \\
\vec{\nabla} \cdot(\epsilon \overrightarrow{\mathrm{E}})=0 \\
\overrightarrow{\mathrm{E}}=-\vec{\nabla} \psi \\
\epsilon=\left(1-e \Delta \mathrm{T}^{*} \mathrm{~T}\right)
\end{gathered}
$$

Where $E_{0}^{*}$ is the root mean square value of the electric field at $z^{*}=0, \Delta T^{*}$ is the temperature difference between the horizontal plates, $\epsilon_{0}$ is the dielectric constant at reference temperature $T_{c}^{*}$ and $\chi_{0}^{*}$ is a reference value for the nanoparticle volume fraction .

In the above equations the non-dimensional parameters are given as follows:

$$
\begin{gathered}
\mathrm{R}_{\mathrm{M}}=\frac{\left[\rho_{0}\left(1-\chi_{0}\right)+\rho_{\mathrm{p}} \chi_{0}\right] \mathrm{LKg}}{\mu \alpha_{\mathrm{m}}} ; \mathrm{R}_{\mathrm{ae}}=\frac{\epsilon_{0}\left(\mathrm{e} \Delta \mathrm{T}^{*} \mathrm{E}_{0}^{*}\right)^{2} \mathrm{~K}}{\mu \alpha_{\mathrm{m}}} ; \sqrt{\mathrm{T}_{\mathrm{A}}}=\frac{2 \rho_{0} \Omega \mathrm{K}}{\gamma \mu} \\
\mathrm{R}_{\mathrm{a}}=\frac{\rho_{0} \mathrm{~g} \beta \Delta \mathrm{T}^{*} \mathrm{LK}}{\mu \alpha_{\mathrm{m}}} ; \mathrm{R}_{\mathrm{N}}=\frac{\left(\rho_{\mathrm{p}}-\rho_{0}\right) g L K \chi_{0}}{\mu \alpha_{\mathrm{m}}} ; \mathrm{N}_{\mathrm{A}}=\frac{\mathrm{D}_{\mathrm{T}}}{\mathrm{D}_{\mathrm{B}} \mathrm{T}_{\mathrm{c}}^{*}} \frac{\Delta \mathrm{T}^{*}}{\chi_{0}^{*}} \\
\mathrm{~N}_{\mathrm{B}}=\frac{\gamma(\rho c)_{\mathrm{p}} \chi_{0}^{*}}{(\rho c)_{\mathrm{f}}} ; \mathrm{L}_{\mathrm{e}}=\frac{\alpha_{\mathrm{m}}}{\mathrm{D}_{\mathrm{B}}} ; \alpha_{\mathrm{m}}=\frac{\mathrm{k}_{\mathrm{m}}}{(\rho \mathrm{c})_{\mathrm{f}}}
\end{gathered}
$$

Such that:

$$
\sigma=\frac{(\rho \mathrm{c})_{\mathrm{m}}}{(\rho \mathrm{c})_{\mathrm{f}}} ; \Delta \mathrm{T}^{*}=\mathrm{T}_{\mathrm{h}}^{*}-\mathrm{T}_{\mathrm{c}}^{*} ; \mathrm{J}_{z}=\frac{\partial \chi}{\partial \mathrm{z}}+\mathrm{N}_{\mathrm{A}} \frac{\partial \mathrm{T}}{\partial \mathrm{z}}
$$

Where $R_{M}$ is the density Rayleigh-Darcy number, $R_{a e}$ is the $A C$ electric Rayleigh - Darcy number, $T_{A}$ is the Taylor - Darcy number, $R_{a}$ is the thermal Rayleigh-Darcy number, $R_{N}$ is the nanoparticle Rayleigh - Darcy number , $N_{A}$ is the modified diffusivity ratio , $N_{B}$ is the modified particle - density increment,$L_{e}$ is the Lewis number and $\alpha_{m}$ is the effective thermal diffusivity of the nanofluid .

\section{B. Basic solutions}

The basic state is quiescent, such that:

$$
\begin{gathered}
\vec{V}_{\mathrm{b}}=\overrightarrow{0} ; \mathrm{T}_{\mathrm{b}}=\mathrm{T}_{\mathrm{b}}(\mathrm{z}) ; \mathrm{P}_{\mathrm{b}}=\mathrm{P}_{\mathrm{b}}(\mathrm{z}) ; \chi_{\mathrm{b}}=\chi_{\mathrm{b}}(\mathrm{z}) ; \epsilon_{\mathrm{b}}=\epsilon_{\mathrm{b}}(\mathrm{z}) \\
\overrightarrow{\mathrm{E}}_{\mathrm{b}}=\mathrm{E}_{\mathrm{b}}(\mathrm{z}) \overrightarrow{\mathrm{e}}_{\mathrm{z}} ; \psi_{\mathrm{b}}=\psi_{\mathrm{b}}(\mathrm{z})
\end{gathered}
$$

The solutions of the basic state are:

$$
\begin{gathered}
\chi_{\mathrm{b}}=\mathrm{N}_{\mathrm{A}} \mathrm{z}+\chi_{0} ; \mathrm{T}_{\mathrm{b}}=1-\mathrm{z} ; \epsilon_{\mathrm{b}}=1+\mathrm{e} \Delta \mathrm{T}^{*} \mathrm{z} \\
\mathrm{E}_{\mathrm{b}}=\frac{1}{\mathrm{e} \Delta \mathrm{T}^{*}\left(1+\mathrm{e} \Delta \mathrm{T}^{*} \mathrm{z}\right)} ; \psi_{\mathrm{b}}=-\frac{1}{\left(\mathrm{e} \Delta \mathrm{T}^{*}\right)^{2}} \log \left(1+\mathrm{e} \Delta \mathrm{T}^{*} \mathrm{z}\right)
\end{gathered}
$$

Such that:

$$
\begin{gathered}
\vec{\nabla} \mathrm{p}_{\mathrm{b}}=-\frac{1}{2} \mathrm{R}_{\mathrm{ae}}\left(\overrightarrow{\mathrm{E}}_{\mathrm{b}} \cdot \overrightarrow{\mathrm{E}}_{\mathrm{b}}\right) \vec{\nabla} \epsilon_{\mathrm{b}}+\left(\mathrm{R}_{\mathrm{a}} \mathrm{T}_{\mathrm{b}}-\mathrm{R}_{\mathrm{N}} \chi_{\mathrm{b}}\right) \overrightarrow{\mathrm{e}}_{\mathrm{z}} \\
\mathrm{p}_{\mathrm{b}}=\mathrm{P}_{\mathrm{b}}+\mathrm{R}_{\mathrm{M}^{\mathrm{z}}}-\frac{1}{2} \mathrm{R}_{\mathrm{ae}} \rho \frac{\partial \epsilon_{\mathrm{b}}}{\partial \rho}\left(\overrightarrow{\mathrm{E}}_{\mathrm{b}} \cdot \overrightarrow{\mathrm{E}}_{\mathrm{b}}\right) \\
\mathrm{E}_{0}^{*}=\frac{-\mathrm{e} \Delta \mathrm{T}^{*} \psi_{1}^{*}}{\operatorname{Llog}\left(1+\mathrm{e} \Delta \mathrm{T}^{*}\right)}
\end{gathered}
$$

Where $\chi_{0}=\left(\chi_{b}^{*}(0)-\chi_{0}^{*}\right) / \chi_{0}^{*}$ is the relative nanoparticle volume fraction at $z=0$

\section{Perturbation equations}

To study the stability of the steady state, we superimpose infinitesimally small perturbations on the basic solutions in the form:

$$
\begin{gathered}
\overrightarrow{\mathrm{V}}=\overrightarrow{\mathrm{V}}^{\prime} ; \mathrm{P}=\mathrm{P}_{\mathrm{p}}+\mathrm{P}^{\prime} ; \mathrm{T}=\mathrm{T}_{\mathrm{p}}+\mathrm{T}^{\prime} ; \chi=\chi_{\mathrm{p}}+\chi^{\prime} \\
\epsilon=\epsilon_{\mathrm{b}}+\epsilon^{\prime} ; \overrightarrow{\mathrm{E}}=\overrightarrow{\mathrm{E}}_{\mathrm{b}}+\overrightarrow{\mathrm{E}}^{\prime} ; \psi=\psi_{\mathrm{p}}+\psi^{\prime}
\end{gathered}
$$

Where $\vec{V}^{\prime}, P^{\prime}, T^{\prime}, \chi^{\prime}, \epsilon^{\prime}, \vec{E}^{\prime}$ and $\psi^{\prime}$ are the perturbed quantities over their equilibrium counterparts.

Substituting the expressions (21) into equations (12)-(19), linearizing the equations, eliminating the pressure from the momentum equation (13) by operating curl twice and retaining the vertical component, we obtain the linear stability equations in the form:

$$
\begin{gathered}
\vec{\nabla} \cdot \overrightarrow{\mathrm{V}}^{\prime}=0 \\
\left(\vec{\nabla}^{2}+\mathrm{T}_{\mathrm{A}} \frac{\partial^{2}}{\partial \mathrm{z}^{2}}\right) \mathrm{w}^{\prime}-\left(\mathrm{R}_{\mathrm{ae}}+\mathrm{R}_{\mathrm{a}}\right) \vec{\nabla}_{2}^{2} \mathrm{~T}^{\prime}+\mathrm{R}_{\mathrm{N}} \vec{\nabla}_{2}^{2} \chi^{\prime} \\
-\mathrm{R}_{\mathrm{ae}} \vec{\nabla}_{2}^{2}\left(\frac{\partial \psi^{\prime}}{\partial \mathrm{z}}\right)=0 \\
\mathrm{w}^{\prime}+\left(\vec{\nabla}^{2}-\mathrm{N}_{\mathrm{A}} \mathrm{N}_{\mathrm{B}} \mathrm{L}_{\mathrm{e}}^{-1} \frac{\partial}{\partial \mathrm{z}}-\frac{\partial}{\partial \mathrm{t}}\right) \mathrm{T}^{\prime}-\mathrm{N}_{\mathrm{B}} \mathrm{L}_{\mathrm{e}}^{-1} \frac{\partial \chi^{\prime}}{\partial \mathrm{z}}=0 \\
\mathrm{~N}_{\mathrm{A}} \gamma^{-1} \mathrm{w}^{\prime}-\mathrm{N}_{\mathrm{A}} \mathrm{L}_{\mathrm{e}}^{-1} \vec{\nabla}^{2} \mathrm{~T}^{\prime}-\left(\mathrm{L}_{\mathrm{e}}^{-1} \vec{\nabla}^{2}-\sigma^{-1} \frac{\partial}{\partial \mathrm{t}}\right) \chi^{\prime}=0 \\
\frac{\partial \mathrm{T}^{\prime}}{\partial \mathrm{z}}+\vec{\nabla}^{2} \psi^{\prime}=0 \\
\epsilon^{\prime}=-\mathrm{e} \Delta \mathrm{T}^{*} \mathrm{~T}^{\prime}
\end{gathered}
$$

Where $\vec{\nabla}_{2}^{2}=\partial^{2} / \partial x^{2}+\partial^{2} / \partial y^{2}$ is the horizontal Laplacian operator.

In non-dimensional form, the boundary conditions become:

$$
\mathrm{w}^{\prime}=\mathrm{T}^{\prime}=\frac{\partial}{\partial \mathrm{z}}\left(\chi^{\prime}+\mathrm{N}_{\mathrm{A}} \mathrm{T}^{\prime}\right)=\frac{\partial \psi^{\prime}}{\partial \mathrm{z}}=0 \text { at } \mathrm{z}=0 ; 1
$$

\section{LINEAR STABILITY ANALYSIS}

For simplicity, we restrict our analysis to two dimensional rolls, so that all physical quantities are independent of $y$ which allows us to define a stream function $F^{\prime}$, such that:

$$
\mathrm{u}^{\prime}=-\frac{\partial \mathrm{F}^{\prime}}{\partial \mathrm{z}} ; \mathrm{w}^{\prime}=\frac{\partial \mathrm{F}^{\prime}}{\partial \mathrm{x}}
$$


Using the definition of stream function, the governing equations (23) - (26) become:

$$
\begin{gathered}
{\left[\left(\frac{\partial^{2}}{\partial \mathrm{x}^{2}}+\frac{\partial^{2}}{\partial \mathrm{z}^{2}}\right)+\mathrm{T}_{\mathrm{A}} \frac{\partial^{2}}{\partial \mathrm{z}^{2}}\right] \frac{\partial \mathrm{F}^{\prime}}{\partial \mathrm{x}}-\left(\mathrm{R}_{\mathrm{ae}}+\mathrm{R}_{\mathrm{a}}\right) \frac{\partial^{2} \mathrm{~T}^{\prime}}{\partial \mathrm{x}^{2}}} \\
+\mathrm{R}_{\mathrm{N}} \frac{\partial^{2} \chi^{\prime}}{\partial \mathrm{x}^{2}}-\mathrm{R}_{\mathrm{ae}} \frac{\partial^{2}}{\partial \mathrm{x}^{2}}\left(\frac{\partial \psi^{\prime}}{\partial \mathrm{z}}\right)=0 \\
\frac{\partial \mathrm{F}^{\prime}}{\partial \mathrm{x}}+\left[\left(\frac{\partial^{2}}{\partial \mathrm{x}^{2}}+\frac{\partial^{2}}{\partial \mathrm{z}^{2}}\right)-\mathrm{N}_{\mathrm{A}} \mathrm{N}_{\mathrm{B}} \mathrm{L}_{\mathrm{e}}^{-1} \frac{\partial}{\partial \mathrm{z}}-\frac{\partial}{\partial \mathrm{t}}\right] \mathrm{T}^{\prime} \\
\mathrm{N}_{\mathrm{A}} \gamma^{-1} \frac{\partial \mathrm{F}^{\prime}}{\partial \mathrm{x}}-\mathrm{N}_{\mathrm{A}} \mathrm{L}_{\mathrm{e}}^{-1}\left(\frac{\partial^{2}}{\partial \mathrm{x}^{2}}+\frac{\partial \chi^{\prime}}{\partial \mathrm{z}}=0\right. \\
-\left[\mathrm{L}_{\mathrm{e}}^{-1}\left(\frac{\partial^{2}}{\partial \mathrm{x}^{2}}+\frac{\partial^{2}}{\partial \mathrm{z}^{2}}\right)-\sigma^{-1} \frac{\partial}{\partial \mathrm{t}}\right] \chi^{\prime}=0 \\
\frac{\partial \mathrm{T}^{\prime}}{\partial \mathrm{z}}+\left(\frac{\partial^{2}}{\partial \mathrm{x}^{2}}+\frac{\partial^{2}}{\partial \mathrm{z}^{2}}\right) \psi^{\prime}=0
\end{gathered}
$$

The equations (29)-(32) are simplified in the usual manner by decomposing the solution in terms of normal modes. According to Borujerdi et al. [18], we can take the perturbation quantities in the form:

$$
\begin{aligned}
\mathrm{F}^{\prime}=\mathcal{F}(\mathrm{z}) \cos (\mathrm{ax}) \exp (\mathrm{nt}) & ; \mathrm{T}^{\prime}=\mathcal{T}(\mathrm{z}) \sin (\mathrm{ax}) \exp (\mathrm{nt}) \\
\chi^{\prime}=\mathcal{X}(\mathrm{z}) \sin (\mathrm{ax}) \exp (\mathrm{nt}) & ; \quad \psi^{\prime}=\Psi(\mathrm{z}) \sin (\mathrm{ax}) \exp (\mathrm{nt})
\end{aligned}
$$

Where $a$ is the horizontal wave number and $n$ is the growth rate of the disturbances.

Substituting the expressions (33) into the differential equations (29) - (32), the linearized equations become:

$$
\begin{gathered}
-\mathrm{a}\left[\left(\mathrm{D}^{2}-\mathrm{a}^{2}\right)+\mathrm{T}_{\mathrm{A}} \mathrm{D}^{2}\right] \mathcal{F}+\mathrm{a}^{2}\left(\mathrm{R}_{\mathrm{ae}}+\mathrm{R}_{\mathrm{a}}\right) \mathcal{T} \\
-\mathrm{a}^{2} \mathrm{R}_{\mathrm{N}} \mathcal{X}+\mathrm{a}^{2} \mathrm{R}_{\mathrm{ae}} \mathrm{D} \Psi=0 \\
-\mathrm{a} \mathcal{F}+\left[\left(\mathrm{D}^{2}-\mathrm{a}^{2}\right)-\mathrm{N}_{\mathrm{A}} \mathrm{N}_{\mathrm{B}} \mathrm{L}_{\mathrm{e}}^{-1} \mathrm{D}-\mathrm{n}\right] \mathcal{T}-\mathrm{N}_{\mathrm{B}} \mathrm{L}_{\mathrm{e}}^{-1} \mathrm{D} \mathcal{X}=0 \\
-\mathrm{aN}_{\mathrm{A}} \gamma^{-1} \mathcal{F}-\mathrm{N}_{\mathrm{A}} \mathrm{L}_{\mathrm{e}}^{-1}\left(\mathrm{D}^{2}-\mathrm{a}^{2}\right) \mathcal{T} \\
-\left[\mathrm{L}_{\mathrm{e}}^{-1}\left(\mathrm{D}^{2}-\mathrm{a}^{2}\right)-\sigma^{-1} \mathrm{n}\right] \mathcal{X}=0 \\
\mathrm{D} \mathcal{T}+\left(\mathrm{D}^{2}-\mathrm{a}^{2}\right) \Psi=0
\end{gathered}
$$

Here $\mathrm{D}=\partial / \partial \mathrm{z}$ and $D^{2}=\partial^{2} / \partial z^{2}$

The boundary conditions of the problem in view of normal mode analysis are:

$$
\mathcal{F}=\mathcal{T}=\mathrm{D}\left(\mathcal{X}+\mathrm{N}_{\mathrm{A}} \mathcal{T}\right)=\mathrm{D} \Psi=0 \text { at } \mathrm{z}=0 ; 1
$$

\section{A. Analytical solution}

The Galerkin weighted residuals technique (GWRT) is used to obtain an analytical solution to the system of equations (34)(37). Accordingly, the base functions $\mathcal{F}, \mathcal{T}, \mathcal{X}$ and $\Psi$ are taken in the following way:

$\mathcal{F}=\sum_{s=1}^{\mathrm{s}=\mathrm{N}} \mathrm{A}_{\mathrm{s}} \mathcal{F}_{\mathrm{s}} ; \mathcal{T}=\sum_{\mathrm{s}=1}^{\mathrm{s}=\mathrm{N}} \mathrm{B}_{\mathrm{s}} \mathcal{T}_{\mathrm{s}} ; \mathcal{X}=\sum_{\mathrm{s}=1}^{\mathrm{s}=\mathrm{N}} \mathrm{C}_{\mathrm{s}} \mathcal{X}_{\mathrm{s}} ; \Psi=\sum_{\mathrm{s}=1}^{\mathrm{s}=\mathrm{N}} \mathrm{D}_{\mathrm{s}} \Psi_{\mathrm{s}}$

The previous base functions must satisfy the boundary conditions (38). For this purpose, we take the solutions in the form:

$$
\mathcal{T}_{\mathrm{s}}=\mathcal{F}_{\mathrm{s}}=\sin (\mathrm{s} \pi \mathrm{z}) ; \mathcal{X}_{\mathrm{s}}=-\mathrm{N}_{\mathrm{A}} \mathcal{T}_{\mathrm{s}} ; \Psi_{\mathrm{s}}=\cos (\mathrm{s} \pi \mathrm{z})
$$

Where $A_{s}, B_{s}, C_{s}$ and $D_{s}$ are unknown coefficients, such that the index $s$ varies between 1 and $N(s=1,2,3 \ldots, N)$.

Substituting the expressions (39) and (40) in the equations (34) - (37) and multiplying the first equation by $\mathcal{F}_{p}$, second equation by $\mathcal{T}_{p}$, third equation by $\mathcal{X}_{p}$ and fourth equation by $\Psi_{p}$, and then integrating in the limits from zero to unity for obtaining a set of $4 \mathrm{~N}$ linear homogeneous equations with $4 \mathrm{~N}$ unknowns $A_{s}, B_{s}, C_{s}$ and $D_{s}$, such that $p=1,2,3 \ldots, N$. For the existence of nontrivial solution, the determinant of coefficients matrix must vanish which gives the characteristic equation for the system with the thermal Rayleigh-Darcy number $R_{a}$ as the eigenvalue of the characteristic equation. The resulting eigenvalue problem is solved analytically by the Galerkin method of first order $(N=1)$ which is given by the following condition:

$$
\operatorname{det}(M)=0
$$

Where:

$$
M=\left(\begin{array}{cccc}
a\left(J+\pi^{2} T_{A}\right) & a^{2}\left(R_{a e}+R_{a}\right) & a^{2} R_{N} N_{A} & -\pi a^{2} R_{a e} \\
-a & -(J+n) & 0 & 0 \\
a \gamma^{-1} & -L_{e}^{-1} J & \left(L_{e}^{-1} J+\sigma^{-1} n\right) & 0 \\
0 & \pi & 0 & -J
\end{array}\right)
$$

$$
J=\pi^{2}+a^{2}
$$

The previous condition (41) allows to give an expression for the dispersion relation in the form:

$$
\mathrm{pn}^{2}+\mathrm{qn}+\mathrm{s}=0
$$

Such that:

$$
\begin{gathered}
n=r+i \omega \\
p=\sigma^{-1}\left(J+\pi^{2} T_{A}\right) J \\
q=\left(\sigma^{-1}+L_{e}^{-1}\right)\left(J+\pi^{2} T_{A}\right) J^{2}-\sigma^{-1} R_{a e} a^{4}-R_{N} N_{A} \gamma^{-1} a^{2} J-\sigma^{-1} R_{a} a^{2} J \\
s=L_{e}^{-1}\left[\left(J+\pi^{2} T_{A}\right) J^{2}-R_{a e} a^{4}\right] J-R_{N} N_{A}\left(\gamma^{-1}+L_{e}^{-1}\right) a^{2} J^{2}-L_{e}^{-1} R_{a} a^{2} J^{2}
\end{gathered}
$$

For the stationary convection, the real and imaginary parts of $n$ are zero. Hence the relation (42) allows us to give the expression of the thermal Rayleigh - Darcy number $R_{a}$ as follows:

$$
\mathrm{R}_{\mathrm{a}}=\frac{\mathrm{J}^{2}+\mathrm{\pi}^{2} \mathrm{~T}_{\mathrm{A}} \mathrm{J}}{\mathrm{a}^{2}}-\mathrm{R}_{\mathrm{ae}} \frac{\mathrm{a}^{2}}{\mathrm{~J}}-\mathrm{R}_{\mathrm{N}} \mathrm{N}_{\mathrm{A}}\left(1+\mathrm{L}_{\mathrm{e}} \gamma^{-1}\right)
$$

To find the critical value of $R_{a}$, the equation (43) is differentiated with respect to $a^{2}$, and then equated to zero. A polynomial in $a_{c}$, whose coefficients are functions of the physical parameters $T_{A}$ and $R_{a e}$ is obtained in the form:

$$
\begin{aligned}
\mathrm{a}_{\mathrm{c}}{ }^{8}+2 \pi^{2} \mathrm{a}_{\mathrm{c}}{ }^{6}-\pi^{2}\left(\pi^{2} \mathrm{~T}_{\mathrm{A}}+\mathrm{R}_{\mathrm{ae}}\right) \mathrm{a}_{\mathrm{c}}{ }^{4} \\
-2 \pi^{6}\left(\mathrm{~T}_{\mathrm{A}}+1\right) \mathrm{a}_{\mathrm{c}}{ }^{2}-\pi^{8}\left(\mathrm{~T}_{\mathrm{A}}+1\right)=0
\end{aligned}
$$

The equation (44) is solved numerically for various values of $T_{A}$ and $R_{a e}$ and the critical value $a_{c}$ is obtained each time using the Newton-Raphson method. The above results coincide with that of P.H.Roberts [1] in the absence of nanoparticles and rotation $\left(R_{N}=T_{A}=0\right)$, Dhananjay Yadav et al. [10] in the absence of rotation $\left(T_{A}=0\right)$ and Ramesh Chand [11] for a thermal equilibrium case in a non-rotating Darcy porous medium $\left(T_{A}=\widetilde{D_{a}}=0\right)$. 
For the oscillatory convection, the real part of $n$ is zero and hence the relation (42) yields the following expressions for the frequency of oscillations $\omega$ and the thermal Rayleigh-Darcy number $R_{a}^{o s c}$ :

$$
q=0 ; \omega^{2}=\frac{s}{p}
$$

From the above results (45), we can write:

$$
\begin{gathered}
\left(\sigma^{-1}+L_{e}^{-1}\right)\left(J+\pi^{2} T_{A}\right) J^{2}-\sigma^{-1} R_{a e} a^{4}-R_{N} N_{A} \gamma^{-1} a^{2} J-\sigma^{-1} R_{a}^{o s c} a^{2} J=0 \\
\omega^{2}=\frac{\left(J+\pi^{2} T_{A}\right) J^{2}-R_{a e} a^{4}-R_{N} N_{A}\left(1+L_{e} \gamma^{-1}\right) a^{2} J-R_{a}^{o s c} a^{2} J}{L_{e} \sigma^{-1}\left(J+\pi^{2} T_{A}\right)}
\end{gathered}
$$

Therefore:

$$
\begin{gathered}
\mathrm{R}_{\mathrm{a}}^{\text {osc }}=\frac{\left(1+\sigma \mathrm{L}_{\mathrm{e}}^{-1}\right)\left(\mathrm{J}+\pi^{2} \mathrm{~T}_{\mathrm{A}}\right) \mathrm{J}^{2}-\mathrm{R}_{\mathrm{ae}} \mathrm{a}^{4}-\mathrm{R}_{\mathrm{N}} \mathrm{N}_{\mathrm{A}} \sigma \gamma^{-1} \mathrm{a}^{2} \mathrm{~J}}{\mathrm{a}^{2} \mathrm{~J}} \\
\omega^{2}=-\left\{\left(\frac{\sigma}{\mathrm{L}_{\mathrm{e}}}\right)^{2} \mathrm{~J}^{2}+\frac{\mathrm{R}_{\mathrm{N}} \mathrm{N}_{\mathrm{A}} \sigma\left(\mathrm{L}_{\mathrm{e}}+\gamma-\sigma\right) \mathrm{a}^{2} \mathrm{~J}}{\gamma \mathrm{L}_{\mathrm{e}}\left(\mathrm{J}+\pi^{2} \mathrm{~T}_{\mathrm{A}}\right)}\right\}
\end{gathered}
$$

If we take $T_{A}=0$ in the above expressions, we find the same results, which are already shown by Dhananjay Yadav et al. [10], when they have studied the electrothermal instability in a Darcy porous medium saturated by a dielectric nanofluid.

From equation (47), it is interesting to note that the vertical $A C$ electric field doesn't influence the existence of oscillatory convection.

According to Yadav et al. [10], Ramesh Chand [11] and Shivakumara et al. [19] the Lewis number $L_{e}$ is on the order of $10^{1}-10^{3}$, the nanoparticle Rayleigh-Darcy number $R_{N}$ is on the order of $10^{0}-10^{1}$, the modified diffusivity ratio $N_{A}$ and the ratio $\sigma$ aren't more than 10 , the porosity $\gamma$ is not more than the unity. Hence, the value of $\omega^{2}$ in the expression (47) will be always negative, which implies that the oscillatory convection is not possible for the studied problem. Therefore, the vertical $A C$ electric field and the uniform rotation have no effect on the existence of the oscillatory convection.

The modified particle-density increment $N_{B}$ doesn't appear in the expression (43) of the thermal Rayleigh- Darcy number $R_{a}$ characterizing the onset of stationary convection, because of an orthogonal property of the first-order trial functions and their first derivatives. Fortunately, this approximation is valid because this term $\left(N_{B} \sim 10^{-3}-10^{-1}\right.$ Shivakumara et al. [19]) appears only in the energy equation (14) as a product with the inverse of the Lewis number $\left(L_{e} \sim 10^{1}-10^{3}\right.$ Yadav et al. [10]) near the temperature gradient and the volume fraction gradient of nanoparticles. So, it makes sense to neglect the effect of the modified particle-density increment $N_{B}$ on the onset of stationary convection.

\section{B. Numerical solution}

The analytical study shows that the oscillatory convection is ruled out for the dielectric nanofluids, so the stationary convection $(n=0)$ is the predominant mode.

Using the power series method (PSM) [20-24], we can solve numerically the equations (34) - (37) in their stationary forms $(n=0)$ by choosing a suitable change of variables that makes the number of variables equal to the number of boundary conditions, after this step we obtain a set of eight first order ordinary differential equations which we can write it in the following form:

$$
\frac{d}{d z} u_{i}(z)=a_{i j} u_{j}(z) ; 1 \leq i, j \leq 8
$$

Such that:

$$
\mathrm{u}_{1}=\mathrm{u}_{3}=\mathrm{u}_{6}=\mathrm{u}_{8}=0 \quad \text { at } \quad \mathrm{z}=0 ; 1
$$

Where:

$$
\begin{gathered}
\mathrm{u}_{1}=\mathcal{F} ; \mathrm{u}_{2}=\mathrm{D} \mathcal{F} ; \mathrm{u}_{3}=\mathcal{T} ; \mathrm{u}_{4}=\mathrm{D} \mathcal{T} ; \mathrm{u}_{5}=\mathcal{X} \\
\mathrm{u}_{6}=\mathrm{D}\left(\mathcal{X}+\mathrm{N}_{\mathrm{A}} \mathcal{T}\right) ; \mathrm{u}_{7}=\Psi ; \mathrm{u}_{8}=\mathrm{D} \Psi
\end{gathered}
$$

The solution of the system (48) in matrix notation can be written as follows:

Where:

$$
\mathrm{U}=\mathrm{BC}
$$

$$
\mathrm{B}=\left(\left(\mathrm{u}_{\mathrm{i}}^{\mathrm{j}}(\mathrm{z})\right)_{\substack{1 \leq \mathrm{i} \leq 8 \\ 1 \leq \mathrm{j} \leq 8}}\right) ; \mathrm{U}=\left(\left(\mathrm{u}_{\mathrm{i}}(\mathrm{z})\right)_{1 \leq \mathrm{i} \leq 8}\right)^{\mathrm{T}} ; \mathrm{C}=\left(\left(\mathrm{c}_{\mathrm{j}}\right)_{1 \leq \mathrm{j} \leq 8}\right)^{\mathrm{T}}
$$

The use of the boundary conditions (49) at $z=0$ allows us to write each variable $u_{i}(z)$ as a linear combination for four functions $u_{i}^{j}(z)$, such that:

$$
\begin{gathered}
\mathrm{u}_{\mathrm{i}}^{\mathrm{j}}(0)=\delta_{\mathrm{ij}} \\
\mathrm{c}_{1}=\mathrm{c}_{3}=\mathrm{c}_{6}=\mathrm{c}_{8}=0
\end{gathered}
$$

Where $\delta_{i j}$ is the Kronecker delta symbol.

After introducing the new expressions of the variables $u_{i}(z)$ in the system (48), we will obtain the following equations:

$$
\frac{\mathrm{d}}{\mathrm{dz}} \mathrm{u}_{\mathrm{i}}^{\mathrm{j}}(\mathrm{z})=\mathrm{a}_{\mathrm{il}} \mathrm{u}_{\mathrm{l}}^{\mathrm{j}}(\mathrm{z}) ; 1 \leq \mathrm{i}, \mathrm{l}, \mathrm{j} \leq 8
$$

For each value of $j$, we must solve a set of eight first order ordinary differential equations which are subjected to the initial conditions (51) by approaching the variables $u_{i}^{j}(z)$ with power series defined in the interval $[0,1]$ and truncated at the order $N$, such that:

$$
u_{i}^{j}(z)=\sum_{p=0}^{p=N} d_{p}^{i, j} z^{p}
$$

A linear combination of the functions $u_{i}^{j}(z)$ satisfying the boundary conditions (49) at $z=1$ leads to a homogeneous algebraic system for the coefficients of the combination, which is written as:

Where:

$$
\mathrm{M}^{\prime} \mathrm{C}^{\prime}=\mathrm{Z}
$$

$$
M^{\prime}=\left(\begin{array}{llll}
u_{1}^{2}(1) & u_{1}^{4}(1) & u_{1}^{5}(1) & u_{1}^{7}(1) \\
u_{3}^{2}(1) & u_{3}^{4}(1) & u_{3}^{5}(1) & u_{3}^{7}(1) \\
u_{6}^{2}(1) & u_{6}^{4}(1) & u_{6}^{5}(1) & u_{6}^{7}(1) \\
u_{8}^{2}(1) & u_{8}^{4}(1) & u_{8}^{5}(1) & u_{8}^{7}(1)
\end{array}\right) ; C^{\prime}=\left(\begin{array}{l}
c_{2} \\
c_{4} \\
c_{5} \\
c_{7}
\end{array}\right) ; Z=\left(\begin{array}{l}
0 \\
0 \\
0 \\
0
\end{array}\right)
$$

A necessary condition for the existence of nontrivial solution is the vanishing the determinant of the matrix $M^{\prime}$ for obtaining the following dispersion relation: 


$$
\mathrm{f}\left(\mathrm{R}_{\mathrm{a}}, \mathrm{a}, \mathrm{T}_{\mathrm{A}}, \mathrm{R}_{\mathrm{ae}}, \mathrm{N}_{\mathrm{B}}, \mathrm{L}_{\mathrm{e}}, \mathrm{R}_{\mathrm{N}}, \mathrm{N}_{\mathrm{A}}, \gamma\right)=\operatorname{det}\left(\mathrm{M}^{\prime}\right)=0
$$

If we give to each control parameter $\left(T_{A}, R_{a e}, N_{B}, L_{e}, R_{N}, N_{A}, \gamma\right)$ its value, we can plot the neutral curve of the stationary convection by the numerical research of the smallest real positive value of the thermal Rayleigh Darcy number $R_{a}$ which corresponds to a fixed wave number $a$ and verifies the dispersion relation (56). After that, we will find a set of points $\left(a, R_{a}\right)$ which help us to plot our curve, and find the critical value $\left(a_{c}, R_{a c}\right)$ which characterizes the onset of the stationary instability, this critical value represents the minimum value of the obtained curve.

\section{RESULTS AND DISCUSSION}

To have a check on the accuracy of the numerical procedure used (PSM) in this study compared to the analytical results $(G W R T)$, the first test computations are carried out for the dielectric fluids in the tables $I$ and $I I\left(R_{N}=0\right)$ and the second tests are reserved to a dielectric nanofluid characterized by $N_{B}=0, L_{e}=40, R_{N}=0.3, N_{A}=2$ and $\gamma=0.9$ in the tables $I I I$ and $I V$ by varying every time the Taylor-Darcy number $T_{A}$ and the $A C$ electric Rayleigh-Darcy number $R_{a e}$.

TABLE I. CRITICAL THERMAL RAYLEIGH-DARCY NUMBER AND CRITICAL WAVE NUMBER FOR DIFFERENT VALUES OF $\mathrm{T}_{\mathrm{A}}$ IN THE CASE WHERE $\mathrm{R}_{\mathrm{N}}=\mathrm{R}_{\mathrm{ae}}=0$

\section{The dielectric fluids case}

\begin{tabular}{cccccccc}
\hline \multirow{2}{*}{$\mathrm{T}_{\mathrm{A}}$} & \multicolumn{3}{c}{ Numerical method } & & \multicolumn{2}{c}{ Analytical method } \\
\cline { 2 - 4 } \cline { 7 - 8 } \cline { 6 - 7 } \cline { 6 - 7 } & $\mathrm{N}$ & $\mathrm{a}_{\mathrm{c}}$ & $\mathrm{R}_{\mathrm{ac}}$ & & $\mathrm{a}_{\mathrm{c}}$ & $\mathrm{R}_{\mathrm{ac}}$ \\
\hline 10 & 17 & 5.7213 & 183.9028 & & 5.7213 & 183.9028 \\
20 & 17 & 6.7251 & 307.5877 & & 6.7251 & 307.5877 \\
40 & 17 & 7.9496 & 540.9159 & & 7.9496 & 540.9159 \\
\hline
\end{tabular}

TABLE II. CRITICAL THERMAL RAYLEIGH-DARCY NUMBER AND CRITICAL WAVE NUMBER FOR DifFERENT VALUES OF $R_{\mathrm{ae}}$ IN THE CASE WHERE $_{\mathrm{A}}=40$ AND $\mathrm{R}_{\mathrm{N}}=0$

The dielectric fluids case

\begin{tabular}{cccccccc}
\hline \multirow{2}{*}{$\mathrm{R}_{\mathrm{ae}}$} & \multicolumn{3}{c}{ Numerical method } & & \multicolumn{2}{c}{ Analytical method } \\
\cline { 2 - 4 } \cline { 7 - 8 } \cline { 6 - 7 } \cline { 6 - 7 } & $\mathrm{N}$ & $\mathrm{a}_{\mathrm{c}}$ & $\mathrm{R}_{\mathrm{ac}}$ & & $\mathrm{a}_{\mathrm{c}}$ & $\mathrm{R}_{\mathrm{ac}}$ \\
\hline 0 & 17 & 7.9496 & 540.9159 & & 7.9496 & 540.9159 \\
50 & 17 & 8.1293 & 497.5393 & & 8.1293 & 497.5393 \\
100 & 17 & 8.3013 & 453.9178 & & 8.3013 & 453.9178 \\
\hline
\end{tabular}

TABLE III. CRITICAL THERMAL RAYLEIGH-DARCY NUMBER AND CRITICAL WAVE NUMBER FOR DiFFERENT VALUES OF $\mathrm{T}_{\mathrm{A}}$ IN THE CASE WHERE $\mathrm{R}_{\mathrm{ae}}=0, \mathrm{~N}_{\mathrm{B}}=0, \mathrm{~L}_{\mathrm{e}}=40, \mathrm{R}_{\mathrm{N}}=0.3, \mathrm{~N}_{\mathrm{A}}=2$ AND $\gamma=0.9$

The dielectric nanofluids case

\begin{tabular}{ccccccc}
\hline \multirow{2}{*}{$\mathrm{T}_{\mathrm{A}}$} & \multicolumn{3}{c}{ Numerical method } & & \multicolumn{2}{c}{ Analytical method } \\
\cline { 2 - 4 } \cline { 6 - 7 } \cline { 6 - 7 } & $\mathrm{N}$ & $\mathrm{a}_{\mathrm{c}}$ & $\mathrm{R}_{\mathrm{ac}}$ & & $\mathrm{a}_{\mathrm{c}}$ & $\mathrm{R}_{\mathrm{ac}}$ \\
\hline 10 & 23 & 5.4532 & 151.9976 & & 5.7213 & 156.6361 \\
20 & 26 & 6.5778 & 277.3816 & & 6.7251 & 280.3210 \\
40 & 29 & 7.8698 & 511.8082 & & 7.9496 & 513.6493 \\
\hline
\end{tabular}

TABLE IV. CRITICAL THERMAL RAYLEIGH-DARCY NUMBER AND CRITICAL WAVE NUMBER FOR DIFFERENT VALUES OF $R_{\text {ae }}$ IN THE CASE WHERE $_{\mathrm{A}}=40, \mathrm{~N}_{\mathrm{B}}=0, \mathrm{~L}_{\mathrm{e}}=40, \mathrm{R}_{\mathrm{N}}=0.3, \mathrm{~N}_{\mathrm{A}}=2$ AND $\gamma=0.9$

\section{The dielectric nanofluids case}

\begin{tabular}{cccccccc}
\hline \multirow{2}{*}{$\mathrm{R}_{\mathrm{ae}}$} & \multicolumn{3}{c}{ Numerical method } & & \multicolumn{2}{c}{ Analytical method } \\
\cline { 2 - 4 } \cline { 7 - 8 } \cline { 6 - 7 } & $\mathrm{N}$ & $\mathrm{a}_{\mathrm{c}}$ & $\mathrm{R}_{\mathrm{ac}}$ & & $\mathrm{a}_{\mathrm{c}}$ & $\mathrm{R}_{\mathrm{ac}}$ \\
\hline 0 & 29 & 7.8698 & 511.8082 & & 7.9496 & 513.6493 \\
50 & 28 & 8.0549 & 468.5429 & & 8.1293 & 470.2726 \\
100 & 30 & 8.2318 & 425.0199 & & 8.3013 & 426.6511 \\
\hline
\end{tabular}

The above tables show that the numerical stationary instability threshold of dielectric fluids and dielectric nanofluids depend implicitly of the truncation order $N$, the Taylor-Darcy number $T_{A}$ and the $A C$ electric Rayleigh-Darcy number $R_{a e}$, such that the truncation order $N_{c}$ which corresponds to the convergence of the numerical method (PSM) is determined, when the absolute value of the difference between the critical thermal Rayleigh-Darcy numbers $R_{a c}\left(N_{c}+1\right)$ and $R_{a c}\left(N_{c}\right)$ is of the order of $10^{-5}$.

Where $R_{a c}\left(N_{c}\right)$ and $R_{a c}\left(N_{c}+1\right)$ are the critical thermal Rayleigh-Darcy numbers which correspond to the truncation orders $N_{c}$ and $N_{c}+1$ respectively, such that:

$$
\mathrm{R}_{\mathrm{ac}}=\mathrm{R}_{\mathrm{ac}}\left(\mathrm{N}_{\mathrm{c}}\right)
$$

A quantitative comparison between the numerical procedure (PSM) and the analytical method (GWRT) shows that there is an excellent agreement between these two methods when we studied the dielectric fluids, but on the contrary we found a remarkable difference between these methods when we treated the dielectric nanofluids, such that $a_{c}(G W R T)>a_{c}(P S M)$ and $R_{a c}(G W R T)>R_{a c}(P S M)$. The observed difference is due principally to the wrong choice of the test function $x_{s}$ characterizing the presence of the nanoparticles in a dielectric base fluid in the case where the nanoparticle flux is taken zero on the horizontal boundaries with $x_{\mathrm{s}}=-\mathrm{N}_{\mathrm{A}} \mathcal{T}_{\mathrm{s}}$. It's important to note that the previous problem doesn't arise if we impose a constant nanoparticle volume fraction at the boundaries of the layer instead to consider a zero nanoparticle flux (A.Wakif et al. [23]).

To give an additional credibility to the trueness of the results obtained by the power series method (PSM) in this investigation, we can compare this numerical procedure with another known numerical method. For this reason, we solve again the system of sixty-four differential equations (53) with the initial conditions (51) using the fourth-order explicit Runge-Kutta method (RKM) on the one hand with a fixed step size $(h=0.01)$; and on the other hand with a variable step size. The results obtained for a dielectric fluid and a dielectric nanofluid are tabulated in the tables $V$ and $V I$, respectively. The comparison between the results obtained with the power series method (PSM) and those found with the RungeKutta methods (RKM) shows the existence of an excellent agreement between the power series method (PSM) and the adaptive step-size control. 
TABLE V. COMParison between the Power SERIES Method (PSM) AND the Runge-KutTa Methods (RKM) FOR A DiElectric Fluid

\begin{tabular}{|c|c|c|c|c|c|c|c|c|}
\hline \multirow{2}{*}{$\mathrm{R}_{\mathrm{ae}}$} & \multirow{2}{*}{$\mathrm{T}_{\mathrm{A}}$} & \multicolumn{3}{|c|}{ PSM } & \multicolumn{2}{|c|}{ RKM with a fixed step size } & \multicolumn{2}{|c|}{ RKM with a variable step size } \\
\hline & & $\mathrm{N}$ & $\mathrm{a}_{\mathrm{c}}$ & $\mathrm{R}_{\mathrm{ac}}$ & $a_{c}$ & $\mathrm{R}_{\mathrm{ac}}$ & $a_{c}$ & $\mathrm{R}_{\mathrm{ac}}$ \\
\hline \multirow{6}{*}{0} & 0 & \multirow{6}{*}{17} & 3.1415 & 39.4784 & 3.1415 & 39.4783 & 3.1415 & 39.4784 \\
\hline & 10 & & 5.7213 & 183.9028 & 5.7213 & 183.9026 & 5.7213 & 183.9027 \\
\hline & 20 & & 6.7251 & 307.5877 & 6.7251 & 307.5874 & 6.7251 & 307.5877 \\
\hline & 30 & & 7.4129 & 425.7306 & 7.4129 & 425.7303 & 7.4129 & 425.7305 \\
\hline & 40 & & 7.9496 & 540.9159 & 7.9496 & 540.9156 & 7.9496 & 540.9159 \\
\hline & 50 & & 8.3954 & 654.1855 & 8.3954 & 654.1851 & 8.3954 & 654.1855 \\
\hline 20 & \multirow{5}{*}{40} & \multirow{5}{*}{17} & 8.0224 & 523.5962 & 8.0224 & 523.5959 & 8.0224 & 523.5962 \\
\hline 40 & & & 8.0940 & 506.2349 & 8.0940 & 506.2346 & 8.0940 & 506.2349 \\
\hline 60 & & & 8.1643 & 488.8338 & 8.1643 & 488.8335 & 8.1643 & 488.8338 \\
\hline 80 & & & 8.2334 & 471.3943 & 8.2334 & 471.3939 & 8.2334 & 471.3943 \\
\hline 100 & & & 8.3013 & 453.9178 & 8.3013 & 453.9175 & 8.3013 & 453.9178 \\
\hline
\end{tabular}

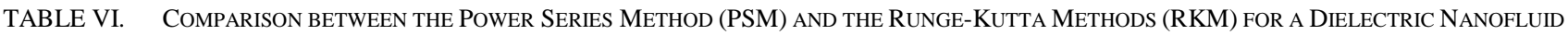
CHARACTERIZED BY $\mathrm{N}_{\mathrm{B}}=0.01, \mathrm{~L}_{\mathrm{e}}=10, \mathrm{R}_{\mathrm{N}}=0.1, \mathrm{~N}_{\mathrm{A}}=0.5$ AND $\gamma=0.3$

\begin{tabular}{|c|c|c|c|c|c|c|c|c|}
\hline \multirow{2}{*}{$\mathrm{R}_{\mathrm{ae}}$} & \multirow{2}{*}{$\mathrm{T}_{\mathrm{A}}$} & \multicolumn{3}{|c|}{ PSM } & \multicolumn{2}{|c|}{ RKM with a fixed step size } & \multicolumn{2}{|c|}{ RKM with a variable step size } \\
\hline & & $\mathrm{N}$ & $a_{c}$ & $\mathrm{R}_{\mathrm{ac}}$ & $\mathrm{a}_{\mathrm{c}}$ & $\mathrm{R}_{\mathrm{ac}}$ & $\mathrm{a}_{\mathrm{c}}$ & $\mathrm{R}_{\mathrm{ac}}$ \\
\hline \multirow{6}{*}{0} & 0 & \multirow{6}{*}{30} & 3.0307 & 36.5544 & 3.0307 & 36.5544 & 3.0307 & 36.5544 \\
\hline & 10 & & 5.7059 & 181.9134 & 5.7059 & 181.9133 & 5.7059 & 181.9134 \\
\hline & 20 & & 6.7163 & 305.6927 & 6.7163 & 305.6925 & 6.7163 & 305.6927 \\
\hline & 30 & & 7.4066 & 423.8767 & 7.4066 & 423.8764 & 7.4066 & 423.8767 \\
\hline & 40 & & 7.9447 & 539.0858 & 7.9447 & 539.0855 & 7.9447 & 539.0858 \\
\hline & 50 & & 8.3914 & 652.3712 & 8.3914 & 652.3709 & 8.3914 & 652.3712 \\
\hline 20 & \multirow{5}{*}{40} & \multirow{5}{*}{30} & 8.0176 & 521.7689 & 8.0177 & 521.7685 & 8.0177 & 521.7689 \\
\hline 40 & & & 8.0893 & 504.4103 & 8.0894 & 504.4099 & 8.0893 & 504.4103 \\
\hline 60 & & & 8.1598 & 487.0117 & 8.1598 & 487.0114 & 8.1598 & 487.0117 \\
\hline 80 & & & 8.2290 & 469.5746 & 8.2290 & 469.5743 & 8.2290 & 469.5746 \\
\hline 100 & & & 8.2970 & 452.1004 & 8.2970 & 452.1001 & 8.2970 & 452.1004 \\
\hline
\end{tabular}

The combined effects of Coriolis forces due to rotation and vertical $A C$ electric field on the criterion for the onset of thermal convection in a dielectric nanofluid saturated a Darcy porous layer are investigated. The bounding surfaces of the dielectric nanofluid are isothermal and subjected to a zero nanoparticle flux. If we neglect the modified particle-density increment $N_{B}$, the numerical procedure and the analytical method carried out for the dielectric nanofluids reveal that the thermal stability of this type of nanofluids depends on six parameters : $T_{A}, R_{a e}, L_{e}, R_{N}, N_{A}$ and $\gamma$.

To study numerically and analytically the effect of a parameter $\left(T_{A}, R_{a e}, N_{B}, L_{e}, R_{N}, N_{A}, \gamma\right)$ on the onset of the electroconvection in a rotating Darcy porous medium filled of a Newtonian dielectric nanofluid with a zero vertical flux of nanoparticles on the isothermal boundaries $\left(z^{*}=0, z^{*}=L\right)$, we must fix the others and determine the variations of the critical wave number $a_{c}$ and the critical thermal Rayleigh Darcy number $R_{a c}$ as a function of the $A C$ electric Rayleigh Darcy number $R_{a e}$ in the interval $[0,50]$ for different values of this parameter and then compare the numerical and analytical results through the curves obtained in Fig. 2 and Fig. 3 .To ensure the accuracy in this study, we will take as truncation order $N_{c}=30$ in all subsequent computations.
The zero boundary conditions for the variables $u_{1}, u_{3}$, $u_{6}, u_{8}$ at $z=0$ and $z=1$ provide a sufficient number of boundary conditions for the system of differential equations (48) to find exactly the thermal Rayleigh-Darcy number $R_{a}$ and the wave number $a$, and also to conclude the critical couple $\left(a_{c}, R_{a c}\right)$ which characterizes the onset of the stationary instability. However, it's difficult to obtain some typical streamlines and isonanofluxes in z-direction (for the nanoparticles) at the onset of convection for a dielectric nanofluid, because this problem requires one more condition named the normalization condition [18] which simply fixes the coefficients $c_{2}, c_{4}, c_{5}, c_{7}$ and allows to find the expressions of the stream function $F$ and the vertical flux of nanoparticles $J_{z}$, and hence to plot the streamlines and the isonanofluxes in Fig. 4 for a dielectric nanofluid. The normalization condition is written as:

$$
\mathrm{u}_{4}=1 \text { at } \mathrm{z}=1
$$

We point out that, the determination of the threshold $\left(a_{c}, R_{a c}\right)$ by the power series method (PSM) and the use of the condition (57), allow us to find the expressions of the stream function $F$ and the vertical flux of nanoparticles $J_{z}$ at the onset of convection with a good accuracy, these expressions are written as follows:

$$
\begin{aligned}
& \mathrm{F}=\mathrm{F}_{\mathrm{b}}+\mathrm{F}^{\prime} \\
& \mathrm{J}_{\mathrm{z}}=\mathrm{J}_{\mathrm{z}_{b}}+\mathrm{J}_{\mathrm{z}}{ }^{\prime}
\end{aligned}
$$


In the expressions (58) and (59), we take:

$$
\begin{gathered}
\mathrm{a}=\mathrm{a}_{\mathrm{c}} ; \mathrm{R}_{\mathrm{a}}=\mathrm{R}_{\mathrm{ac}} ; \mathrm{F}_{\mathrm{b}}=\mathrm{J}_{\mathrm{z}_{\mathrm{b}}}=0 ; \mathrm{F}^{\prime}=\mathrm{u}_{1} \cos (\mathrm{ax}) ; \mathrm{J}_{\mathrm{z}}{ }^{\prime}=\mathrm{u}_{6} \sin (\mathrm{ax}) \\
\mathrm{u}_{1}=\mathrm{c}_{2} \mathrm{u}_{1}^{2}(\mathrm{z})+\mathrm{c}_{4} \mathrm{u}_{1}^{4}(\mathrm{z})+\mathrm{c}_{5} \mathrm{u}_{1}^{5}(\mathrm{z})+\mathrm{c}_{7} \mathrm{u}_{1}^{7}(\mathrm{z}) \\
\mathrm{u}_{6}=\mathrm{c}_{2} \mathrm{u}_{6}^{2}(\mathrm{z})+\mathrm{c}_{4} \mathrm{u}_{6}^{4}(\mathrm{z})+\mathrm{c}_{5} \mathrm{u}_{6}^{5}(\mathrm{z})+\mathrm{c}_{7} \mathrm{u}_{6}^{7}(\mathrm{z})
\end{gathered}
$$

Where $J_{z_{b}}$ and $F_{b}$ are the basic states of the vertical flux of nanoparticles and the stream function, respectively.
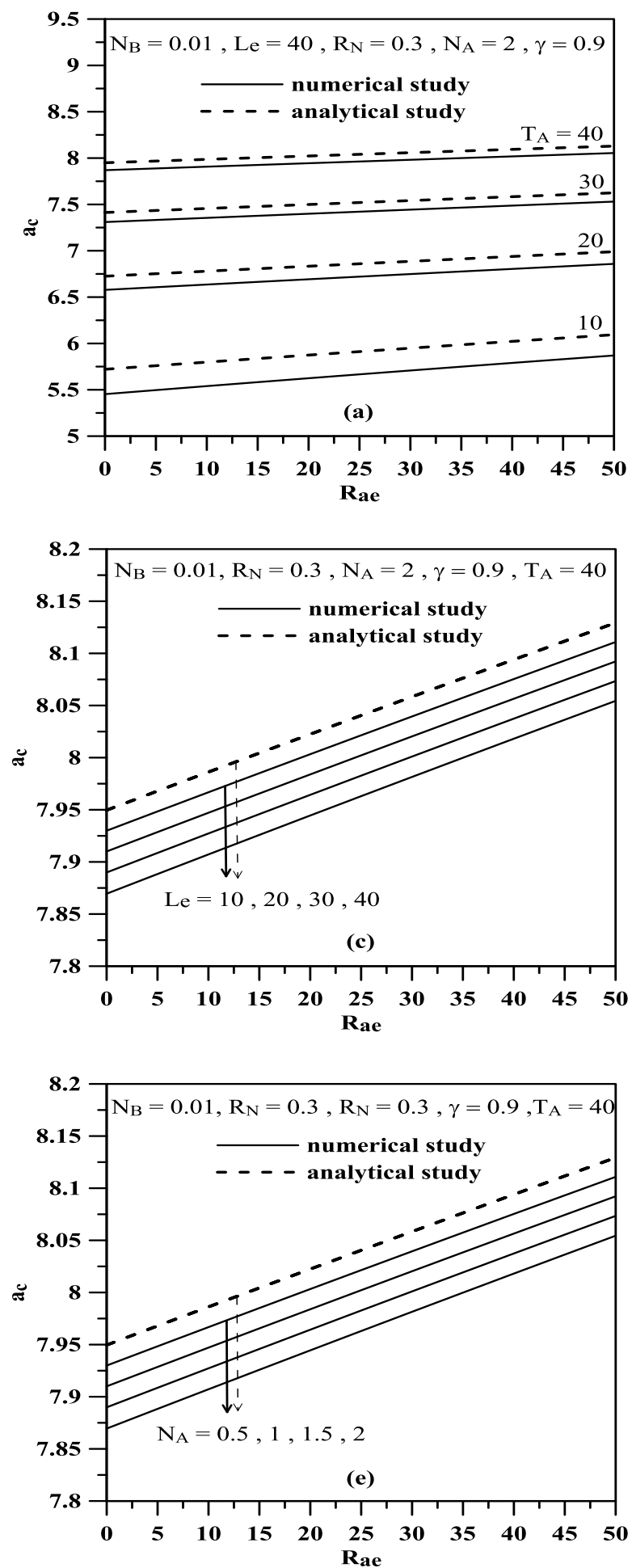

Fig. 2. Plot of $a_{\mathrm{c}}$ as a function of $R_{a e}$ for different values of $(a) T_{A}$
From the expressions (58) and (59), we can conclude the expressions of the Darcy's velocity $V$ and the vertical flux of nanoparticles $J_{z}$, and hence we can plot the variation of $V$ and $J_{z}$ as a function of $z$ in Fig. 5 and Fig. 6 respectively at different positions of $x$, such that:

$$
\mathrm{V}=\sqrt{\left(-\frac{\partial \mathrm{F}}{\partial \mathrm{z}}\right)^{2}+\left(\frac{\partial \mathrm{F}}{\partial \mathrm{x}}\right)^{2}}
$$
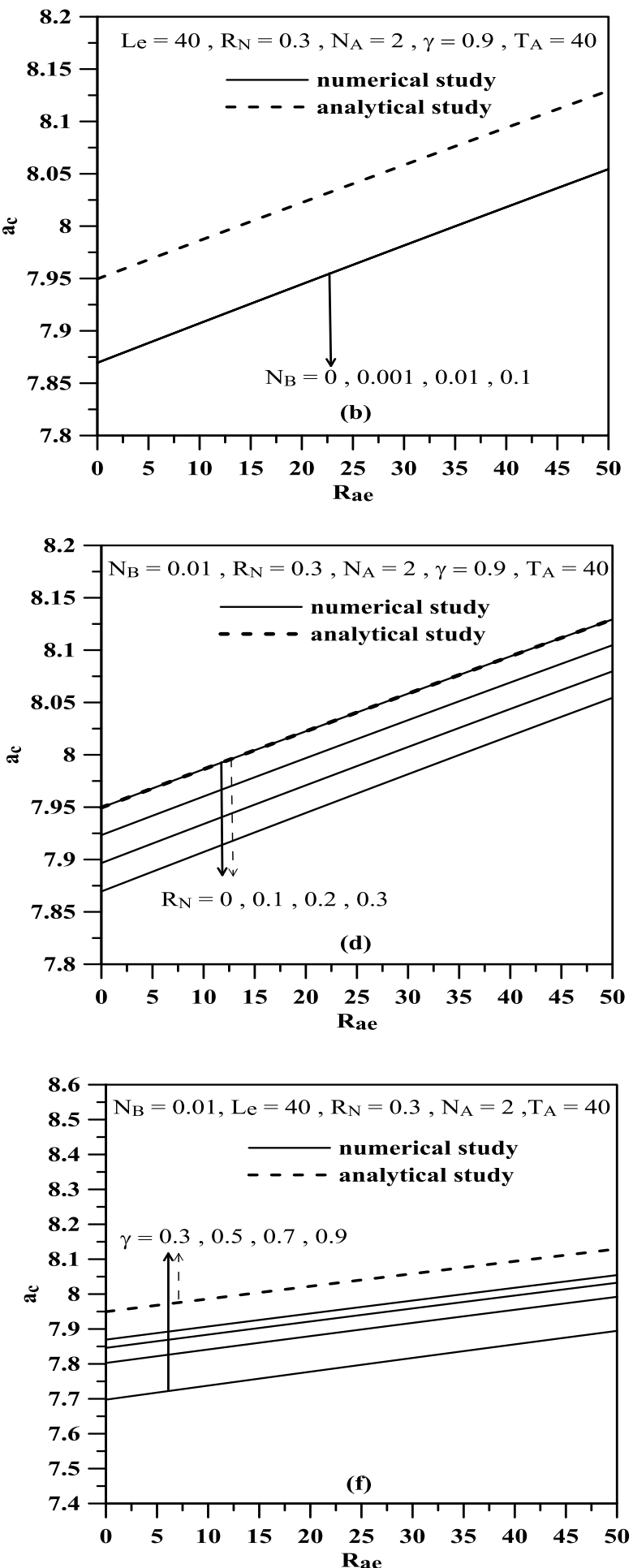

, (b) $N_{B},(c) L_{e},(d) R_{N},(e) N_{A}$ and $(f) \gamma$ for a dielectric nanofluid 

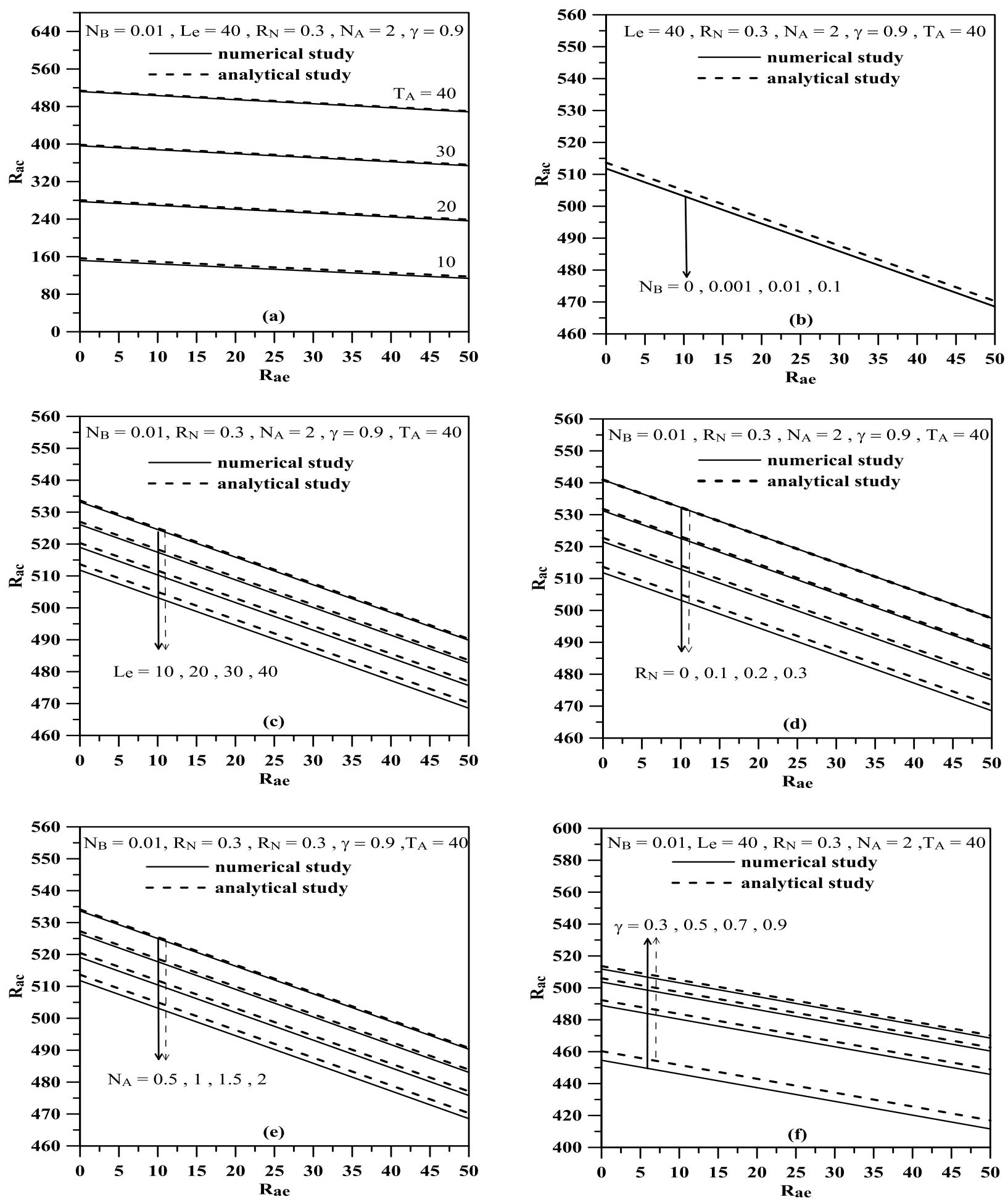

Fig. 3. Plot of $R_{\mathrm{ac}}$ as a function of $R_{a e}$ for different values of $(a) T_{A},(b) N_{B},(c) L_{e},(d) R_{N},(e) N_{A}$ and $(f) \gamma$ for a dielectric nanofluid 

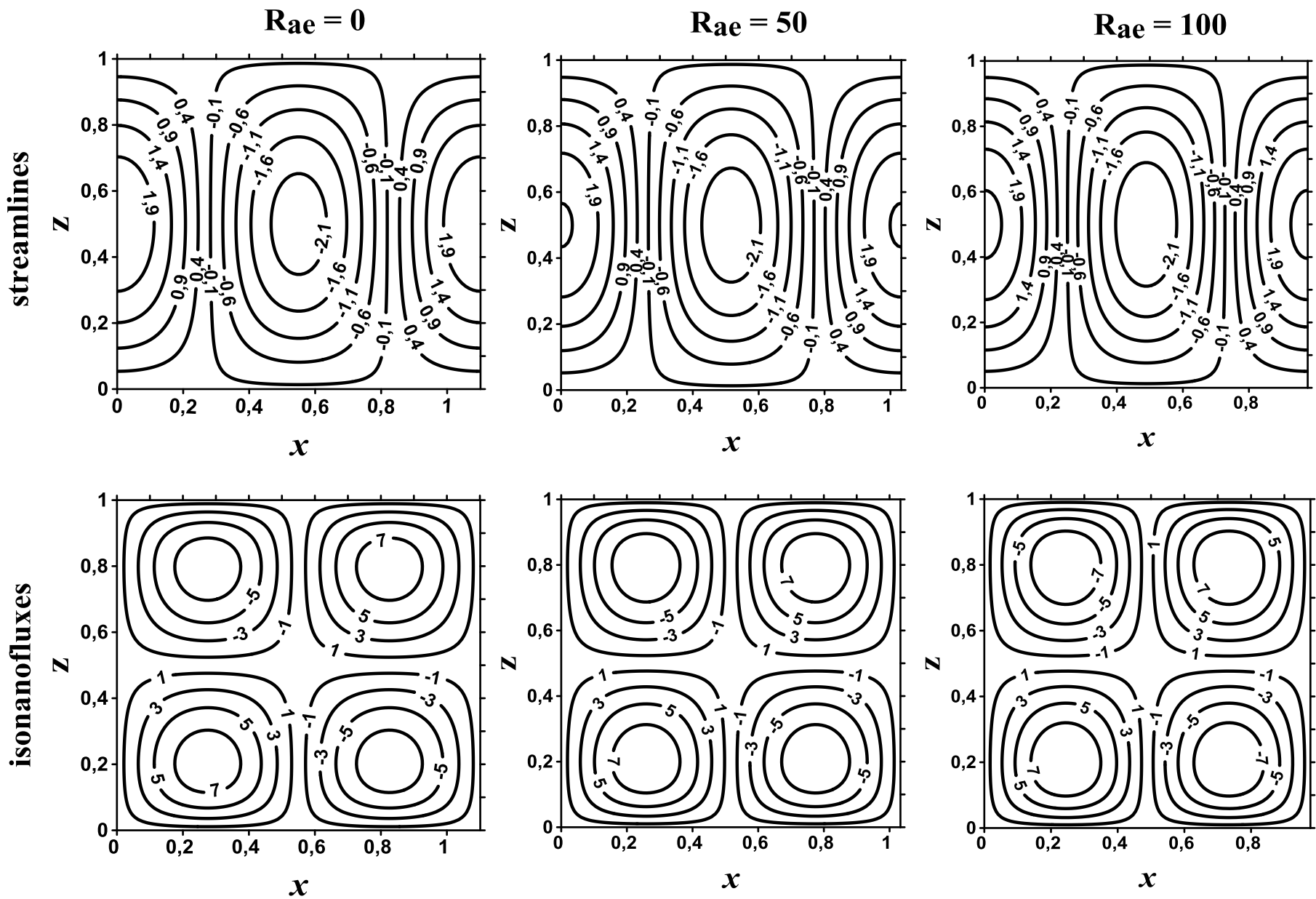

$$
\mathrm{a}_{\mathrm{c}}=5.7059, \mathrm{R}_{\mathrm{ac}}=181.9134
$$

$$
a_{c}=6.0814, R_{a c}=142.9749
$$

$$
a_{c}=6.4243, R_{a c}=103.0501
$$

Fig. 4. Variation in streamlines and isonanofluxes at different values of $R_{a e}$ for a dielectric nanofluid characterized by $N_{B}=0.01, L_{e}=10, R_{N}=0.1$, $N_{A}=0.5, \gamma=0.3$ and $T_{A}=10$
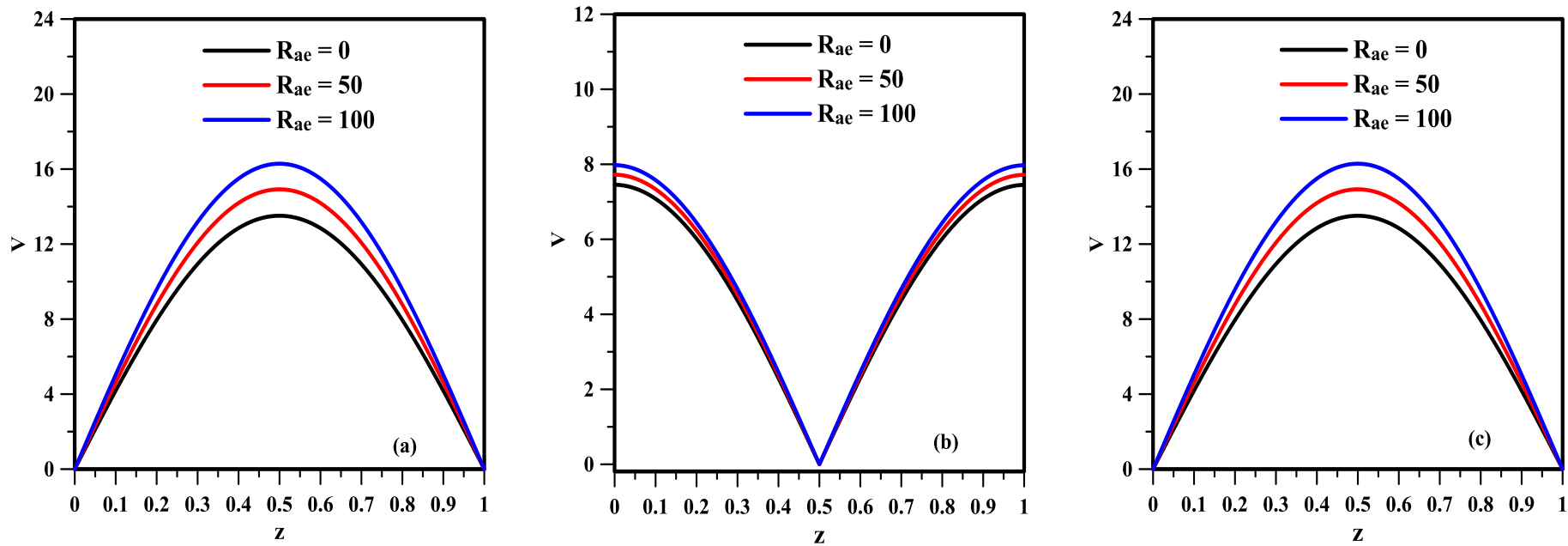

Fig. 5. Plot of $V$ as a function of $z$ for different values of $R_{a e}$ at $(a) x=\pi / 2 a_{c}$, (b) $x=\pi / a_{c}$ and $(c) x=3 \pi / 2 a_{c}$ for a dielectric nanofluid characterized by $N_{B}=0.01, L_{e}=10, R_{N}=0.1, N_{A}=0.5, \gamma=0.3$ and $T_{A}=10$ 

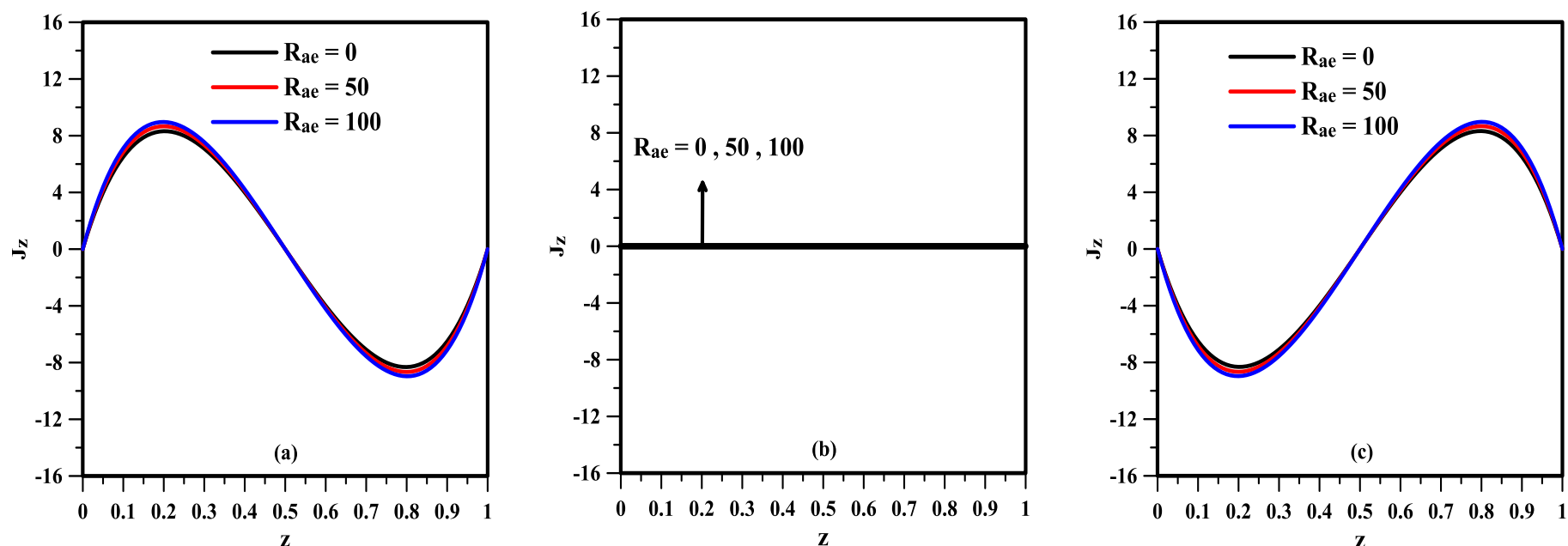

Fig. 6. Plot of $J_{z}$ as a function of $z$ for different values of $R_{a e}$ at $(a) x=\pi / 2 a_{c},(b) x=\pi / a_{c}$ and $(c) x=3 \pi / 2 a_{c}$ for a dielectric nanofluid characterized by $N_{B}=0.01, L_{e}=10, R_{N}=0.1, N_{A}=0.5, \gamma=0.3$ and $T_{A}=10$

For the numerical study, we find from Fig.2 that the critical wave number $a_{a c}$ increases with an increase either in the Taylor-Darcy number $T_{A}$, in the AC electric Rayleigh-Darcy number $R_{a e}$ or in the porosity of the medium $\gamma$. However, it decreases when the Lewis number $L_{e}$, the nanoparticles Rayleigh-Darcy number $R_{N}$ or the modified diffusivity ratio $N_{A}$ increases. Hence, an increase in the parameters $T_{A}, R_{a e}$ or $\gamma$ allows to reduce the size of convection cells (see Fig.4) and an increase in the parameters $L_{e}, R_{N}$ or $N_{A}$ allows to increase also the size of convection cells. On the contrary, we find that the modified particle-density increment $N_{B}$ has no significant effect on the critical wave number $a_{c}$.

Fig.3 (a) shows the variation of the critical thermal Rayleigh-Darcy number $R_{a c}$ as a function of $A C$ electric Rayleigh-Darcy number $R_{a e}$ for different values of the TaylorDarcy number $T_{A}$, indicating that the variation in the critical thermal Rayleigh-Darcy number $R_{a c}$ with the Taylor-Darcy number $T_{A}$ is an increasing function in both studied cases (numerical and analytical), this result shows that the presence of the Coriolis forces allows to minimize the effect of the buoyancy forces on the onset of electroconvection in dielectric nanofluids, and hence the Taylor-Darcy number $T_{A}$ has a stabilizing effect for the dielectric nanofluids.

Fig.3 (b) shows the effect of the modified particle-density increment $N_{B}$ on the onset of electroconvection in dielectric nanofluids. From Fig.3 (b), it's observed that the modified particle-density increment $N_{B}$ has no significant effect on the onset of electroconvection in a dielectric nanofluid. This is happened due to the weak value of the term $N_{B} L_{e}^{-1}$ in the energy equation (14). The product $N_{B} L_{e}^{-1}$ is on the order of $10^{-6}-10^{-2}$, such that the effect of this parameter on the thermal stability of dielectric nanofluids is very small which we can neglect it in the equation (14), this remark is in good agreement with the obtained analytical results, such that the parameter $N_{B}$ doesn't appear in the expression (43) of the thermal Rayleigh-Darcy number $R_{a}$.

Fig.3 (c) shows the variation of the critical thermal Rayleigh-Darcy number $R_{a c}$ as a function of $A C$ electric Rayleigh-Darcy number $R_{a e}$ for different values of the Lewis number $L_{e}$. It is found that the critical thermal RayleighDarcy number $R_{a c}$ decreases analytically and numerically when the value of Lewis number $L_{e}$ increases, indicating that the Lewis number has a destabilizing effect on the dielectric nanofluids. Hence, to ensure the stability of the system, we can use a dielectric nanofluid characterized by a less effective thermal diffusivity.

The variation of the critical thermal Rayleigh-Darcy number $R_{a c}$ as a function of $A C$ electric Rayleigh-Darcy number $R_{a e}$ for different values of the nanoparticles RayleighDarcy number $R_{N}$ is shown in Fig.3 (d). It's observed that the critical thermal Rayleigh-Darcy number $R_{a c}$ decreases analytically and numerically when the nanoparticles RayleighDarcy number $R_{N}$ increases, This is because as an increase in the volumetric fraction of nanoparticles allows to increase both the Brownian motion and the thermophoresis of nanoparticles which cause a destabilizing effect on the stability of the system. Hence, we can consider that the thermophoresis and the Brownian motion as driving forces favoring the motion of the nanoparticles.

Fig.3 (e) shows the variation of the critical thermal Rayleigh-Darcy number $R_{a c}$ as a function of $A C$ electric Rayleigh-Darcy number $R_{a e}$ for different values of the modified diffusivity ratio $N_{A}$, this figure indicates that an increase in the modified diffusivity ratio $N_{A}$ allows to accelerate the onset of electroconvection in the dielectric nanofluids in both studied cases (numerical and analytical). 
Therefore an increase in the temperature difference between the horizontal plates increases also the buoyancy forces which destabilize the system.

Fig.3 (f) shows the variation of the critical thermal Rayleigh-Darcy number $R_{a c}$ as a function of $A C$ electric Rayleigh-Darcy number $R_{a e}$ for different values of the porosity of the medium $\gamma$. It's found that the porosity parameter $\gamma$ delays the onset of electroconvection in the dielectric nanofluids for both studied cases (numerical and analytical). Hence, it has a stabilizing effect. This result shows that the space occupied by a dielectric nanofluid in a porous medium has an important role on the thermal stability of dielectric nanofluids.

From Fig.2 - Fig.6, we find generally that the critical thermal Rayleigh-Darcy number $R_{a c}$ decreases with an increase in the value of the $A C$ electric Rayleigh-Darcy number $R_{a e}$, this result can be explained by the increase in the electrostatic energy which allows to increase both the velocity of the dielectric nanofluid $V$ and the vertical flux of nanoparticles $J_{z}$ at the onset of electroconvection (Fig.5 and Fig.6) , and hence the $A C$ electric Rayleigh-Darcy number $R_{a e}$ has a destabilizing effect for the dielectric nanofluids .

\section{CONCLUSION}

In this paper, we have examined the simultaneous effect of rotation and a vertical $A C$ electric field on the onset of electroconvection in a horizontal dielectric nanofluid layer saturated a Darcy porous medium. The analysis has been performed for zero flux nanoparticles condition at horizontal boundaries, such that these latter are taken as isothermal where $T_{h}^{*}>T_{c}^{*}$. The resulting eigenvalue problem is solved analytically and numerically using the Galerkin weighted residuals technique and the power series method, respectively. The behavior of various parameters like the Taylor - Darcy number $T_{A}$, the modified particle-density increment $N_{B}$, the Lewis number $L_{e}$, the nanoparticle Rayleigh - Darcy number $R_{N}$, the modified diffusivity ratio $N_{A}$, the porosity of the porous medium $\gamma$ and the $A C$ electric Rayleigh - Darcy number $R_{a e}$ on the onset of electroconvection has been analysed and presented graphically.

The principal results derived from the present analysis can be summarized as follows:

- The increase in the porosity of the medium $\gamma$ and the presence of the Coriolis forces allow to stabilize the dielectric nanofluids.

- The Lewis number $L_{e}$, the nanoparticle RayleighDarcy number $R_{N}$, the modified diffusivity ratio $N_{A}$ and the $A C$ electric Rayleigh-Darcy number $R_{a e}$ have a destabilizing effect on the stationary convection.
- The presence of an $A C$ electric field allows to reduce the size of convection cells in the dielectric nanofluids.

- The modified particle-density increment $N_{B}$ has no significant effect on the convective instability for the nanofluids. Hence, we can neglect the contribution of this parameter in the energy equation.

- The oscillatory convection has been ruled out in this problem.

- Qualitatively, there is a good agreement between the analytical and numerical method. Contrariwise, we find a difference in the results between these two methods when we treated the dielectric nanofluids with a zero nanoparticle flux on the horizontal boundaries, this difference will disappear when we consider the case of dielectric fluids.

\section{ACKNOWLEDGEMENTS}

The authors wish to express their very sincerely thanks to the reviewers for their valuable and lucid comments which have improved the paper appreciably.

\section{REFERENCES}

[1] P.H. Roberts, Electrohydrodynamic convection, Quarterly Journal of Mechanics and Applied Mathematics, vol.22, pp.211-220, 1969.

[2] M. Takashima , K.D. Aldridge , The stability of a horizontal layer of dielectric fluid under the simultaneous action of a vertical DC electric field and vertical temperature gradient, Quarterly Journal of Mechanics and Applied Mathematics, vol. 29 ,pp.71-87,1976.

[3] Peter J. Stiles, Electro-thermal convection in dielectric liquids, Chemical Physics Letters, vol. 179, n. 3, pp.311-315, 1991.

[4] Mohamed I.A Othman, Electrohydrodynamic stability in a horizontal viscoelastic fluid layer in the presence of a vertical temperature gradient, International Journal of Engineering Science, vol. 39, pp.1217-1232, 2001.

[5] M. Takashima, The effect of rotation on electrohydrodynamic instability, Can.J.Phy. vol. 54, pp.342-347, 1976.

[6] I. S. Shivakumara, N. Rudraiah, Jinho Lee, K. Hemalatha, The Onset of Darcy-Brinkman Electroconvection in a Dielectric Fluid Saturated Porous Layer, Transp. Porous Med., vol. 90, pp.509-528, 2011.

[7] I. S. Shivakumara, Chiu-On Ng, M.S. Nagashree, The onset of electrothermoconvection in a rotating Brinkman porous layer , International Journal of Engineering Science, vol. 49, n. 7, pp.646-663, 2011

[8] P.G.Siddheshwar, D.Radhakrishna, Linear and nonlinear electroconvection instability under AC electric field, Communications in Nonlinear Science and Numerical Simulation, vol. 17, pp.2883-2895, 2012

[9] F.Asadzadeh, M.Nasr Esfahany, N. Etesami, Natural convective heat transfer of $\mathrm{Fe}_{3} \mathrm{O}_{4} /$ ethylene glycol nanofluid in electric field, International Journal of Thermal Sciences, vol. 62, pp. 114-119, 2012.

[10] Dhananjay Yadav, Jinho Lee, Hyung Hee Cho, Electrothermal instability in a porous medium layer saturated by a dielectric nanofluid, Journal of Applied Fluid Mechanics, vol. 9, in press,2015.

[11] Ramesh Chand, Electro-thermal convection in a Brinkman porous medium saturated by nanofluid, Ain Shams Engineering Journal, 2015. http://dx.doi.org/10.1016/j.asej.2015.10.008

[12] J. Buongiorno, Convective transport in nanofluids, Journal of Heat Transfer, vol.128, pp.240-250, 2006. 
[13] D.Y. Tzou, Thermal instability of nanofluids in natural convection, International Journal of Heat and Mass Transfer, vol.51, pp.2967-2979, 2008.

[14] D.Y. Tzou, Instability of nanofluids in natural convection, ASME Journal of Heat Transfer, 130, 2008, 372-401.

[15] D.A. Nield and A.V. Kuznetsov, Thermal instability in a porous medium layer saturated by a nanofluid: a revised model, International Journal of Heat and Mass Transfer, vol.68, pp.211-214, 2014.

[16] L.D.Landau, E.M. Lifshitz, Electrodynamics of Continuous Media (Pergamon Press, London, 1960).

[17] I.S.Shivakumara, M.Akkanagamma, Chiu-On Ng, Electrohydrodynamic instability of a rotating couple stress dielectric fluid layer, International Journal of Heat and Mass Transfer, vol. 62, pp.761-771, 2013.

[18] A.N.Borujerdi, A.R.Noghrehabadi, D.A.S. Rees, Influence of Darcy number on the onset of convection in a porous layer with a uniform heat source, International Journal of Thermal Sciences, vol. 47, pp.10201025, 2008.

[19] I.S. Shivakumara, M. Dhananjaya and Chiu-On Ng, Thermal convective instability in an Oldroyd-B nanofluid saturated porous layer, International Journal of Heat and Mass Transfer, vol.84, pp.167-177, 2015.
[20] A.Wakif , Z.Boulahia, R.Sehaqui , A Realistic Approach for Studying the Effect of an Internal Heat Source on the Onset of Convection in a Newtonian Nanofluid Layer: rigid-rigid case , IOSR-Journal of Mathematics,vol.11, pp.21-30, 2015.

[21] A.Wakif, R.Sehaqui, A Realistic Study of the Rayleigh-Bénard Problem in the Newtonian Nanofluids with a Uniform Heat Source: Free-Free Case, International journal of science and research, vol.4, pp. 611-615, 2015.

[22] A.Wakif , Z.Boulahia , R.Sehaqui, An accurate method to Study the Rayleigh-Bénard Problem in a Rotating Layer Saturated by a Newtonian Nanofluid , International Journal of Innovation and Scientific Research,vol.20,n.1, pp.25-37, 2016.

[23] A. Wakif , Z. Boulahia , M. Zaydan , N.Yadil and R.Sehaqui, The Power Series Method to Solve a Magneto-Convection Problem in a Darcy-Brinkman Porous Medium Saturated by an Electrically Conducting Nanofluid Layer, International Journal of Innovation and Applied Studies,vol.14, n.4, pp.1048-1065,2016.

[24] A.Wakif , Z.Boulahia, R.Sehaqui , Numerical Study of a Thermal Convection Induced by a Purely Internal Heating in a Rotating Medium Saturated by a Radiating Nanofluid, International Journal of Computer Applications,vol.135,n.10, pp.33-42, 2016. 